\title{
Fifth ERDA Workshop on Personnel Neutron Dosimetry
}

May 6-7, 1975

Washington, DC

Prepared for the U.S. Energy

Research and Development Administration under Contract E(45-1): 1830 
This report was prepared as an account of work sponsored by the United States Government. Neither the United States nor the United States Energy Research and Development Administration, nor any of their emplovees. nor any of their contractors, subcontractors, or their employees, makes any warranty, express or implied or assumes any legal liability or responsibility for the accuracy, completeness or usefulness of any information. apparatus, product or process disclosed, or represents that its use would not infringe privately owned rights.

PACIFIC NORTHWEST LABORATORY

operated by

BATTELLE

for the

U.S. ENERGY RESEARCH AND DEVELOPMENT ADMINISTRATION

Under Contract E(45-1)-1830

\author{
Printed in the United States of America \\ Available from \\ National Technical Information Service \\ U.S. Department of Commerce \\ 5285 Port Royal Road \\ Springfield, Virginia 22151
}

Price: Printed Copy \$5.45; Microfiche \$2.25 
BNWL-1934

UC -48

FIFTH ERDA WORKSHOP ON PERSONNEL NEUTRON DOSIMETRY

Meeting Coordinator:

Edward J. Vallario

U.S. Energy Research and Development Administration

Meeting Program Chairman:

Dale E. Hankins

Lawrence Livermore Laboratory

Scientific Secretary:

Carl M. Unruh

Battelle Memorial Institute

Pacific Northwest Laboratory

Richland, Washington

May 6-7, 1975

Washington, DC 
INDEX

Page

Participants. . . . . . . . . . . . . . . . . . . 1

Surmmary . . . . . . . . . . . . . . . . . . . 3

Radiation Protection Bureau . . . . . . . . . . . . 5

Oak Ridge National Laboratory. . . . . . . . . . . . 6

Los Alamos Scientific Laboratory . . . . . . . . . . . . 9

Chalk River Nuclear Laboratories . . . . . . . . . . 12

Brookhaven National Laboratory . . . . . . . . . . 20

Battelle-Northwest. . . . . . . . . . . . . . 32

Health and Safety Laboratory . . . . . . . . . . . 35

Lawrence Livermore Laboratory . . . . . . . . . . . 38

Lawrence Livermore Laboratory . . . . . . . . . . . . . 43

Savannah River Laboratory . . . . . . . . . . . . 54

Brookhaven National Laboratory . . . . . . . . . . 58

Stanford Linear Accelerator Center . . . . . . . . . . 60

Physikalisch-Technische Bundesanstalt . . . . . . . . 64

Berkeley Nuclear Laboratories . . . . . . . . . . . . 68

Argonne National Laboratory. . . . . . . . . . . . 69 


\section{Participants}

V. Ba la subrahmanyam

Department of National Health and Welfare

Ottawa, Ontario

Canada

Dr. Klaus Becker

Health Physics Division

Oak Ridge National Laboratory

P. O. Box $X$

Oak Ridge, TN 27830

A. W. Blackstock

University of California

Los Alamos Scientific Laboratory

P. 0. Box 1663

Los Alamos, NM 87545

Sy Block

U. S. Nuclear Regulatory Commission Washington, DC

Robert L. Butenhoff

U. S. Energy Research and

Development Administration

Washington, DC

R. S. Caswell

Nationa 1 Bureau of Standards

Washington, DC 20234

Jan Cusimano

Health Physics Laboratory

U. S. Energy Research and Development Administration

P. 0. Box 2108

Idaho Fal1s, ID 83401

Carl Distenfeld

Associated Universities, Inc.

Brookhaven National Laboratory

Upton, NY 11973

Margarete Ehrlich

National Bureau of Standards

Washington, DC
Bill Endres

Battel le-Northwest

P. 0. Box 999

Richland, WA 99352

Roger Falk

The Dow Chemical Company

Rocky Flats Division

P. 0. Box 888

Golden, CO 80401

Leo Faust

Battelle-Northwest

P. 0. Box 999

Richland, WA 99352

Ferene Hajna 1

Radiation Physics Division

U. S. Energy Research and

Development Administration

Health and Safety Lab-NY

376 Hudson Avenue

New York, NY 10014

Da le E. Hankins

University of California

Lawrence Livermore Laboratory

Livermore, CA 94550

Harry Howe

Accelerator Section

Accelerator Laboratory

P. 0. Box 500

Batavia, IL 60510

Jack Hoy

E. I. duPont de Nemours and Co.

Savannah River Plant

Aiken, SC 29801

James E. McLaughl in

U. S. Energy Research and Development Administration

30 Bowdon Road

Greenlawn, NY 11740 


\section{Participants (contd)}

L. F. Phillips

Health Physics and Safety Division

Brookhaven National Laboratory

Upton, NY 11973

Jacob Sedlet

Argonne National Laboratory

9700 S. Cass Avenue

Argonne, IL 60439

Bill Swanson

Stanford Linear Accelerator Center Stanford, CA 94305

I. M. G. Thompson

Central Electricity Generating Board

Berkeley Nuclear Laboratories

Gloucestershire, GL 139 PB
Carl M. Unruh

Battelle-Northwest

P. 0. Box 999

Richland, Washington 99352

E. J. Vallario

U. S. Energy and Research Development Administration Washington, OC 20545

T. J. Yule

Argonne National Laboratory Applied Physics Division 9700 South Cass Avenue Argonne, IL 60439 


\section{FIFTH ERDA WORKSHOP ON PERSONNEL NEUTRON DOSIMETRY}

\section{SUMMARY}

The first AEC Workshop on Personnel Neutron Dosimetry was held September 23-24, 1969 in Bethesda, Maryland and reported as BNWL-1340. The second Workshop was held July 8-9, 1971 in New York City and reported as BNWL-1616. The third Workshop was held March 16-17, 1972 in Savannah River Plant, Georgia, but no documented summary of the third Workshop was prepared. The fourth Workshop was held June 14-15, 1973 in Miami Beach, Florida and was reported as BNWL-1717. The fifth Workshop was held May 6-7, 1975 at the National Bureau of Standards, Washington, DC.

Those participating in the fifth Workshop prepared summary reports of their recent work for inclusion in this document. The reports are reproduced here as submitted by the participants.

Of special interest at this meeting was the report by the National Bureau of Standards of the availability of new low energy monoenergetic neutron calibration facilities. In cooperation with ERDA, and principally by the efforts of the Workshop Chairman, E. J. Vallario, the National Bureau of Standards has equipped their reactor facility with special ports to provide these high purity neutron beams. By using a manganese scatterer followed by a scandium filter, a high purity beam of $2 \mathrm{keV}$ neutrons is obtained. By using a titanium scatterer followed by an iron filter, a monoenergetic beam of $25 \mathrm{keV}$ neutrons is obtained.

The $2 \mathrm{keV}$ spectrum contains about 3 percent higher energy neutrons while $25 \mathrm{keV}$ spectrum is betier than 99 percent at the $25 \mathrm{keV}$ energy level. By using the available scanner, both beams can be applied to an experimental area measuring $18 \times 25$ inches.

At $2 \mathrm{keV}, 6.5 \times 10^{5}$ neutrons $/ \mathrm{sec}$ can be delivered to the experimental area while for the $25 \mathrm{keV}$ beam, $5 \times 10^{6}$ neutrons $/ \mathrm{sec}$ can be delivered to the experimental area. The actual dose rates are a 
function of the experimental area scanned and the reactor operating power levels. For both of these beams, gamma radiation levels to a few mR per hour will also be present.

Those participating in the conference were encouraged to make use of these special neutron facilities for their neutron dosimetry research and development programs as we11 as special studies that could benefit from such irradiation.

Work is in progress at National Bureau of Standards with a silicon filter to develop a pure $144 \mathrm{keV}$ neutron source. A thermal energy neutron beam of $5 \times 10^{5}$ to $10^{9}$ neutrons/sec is available. 
PERSONNEL NELITRON DOSIMETRY AT RADIATION PROTECTION BUREAU

\author{
V. Balasubrahmanyam \\ Radiation Protection Bureau \\ Department of Health and Welfare \\ Ottawa, Canada
}

Canada has a relatively large National Dosimetry Service in operation since 1951. In 1974 approximately 800,000 films were processed and dosimetry services were provided to 50,000 people at 7,000 organizations. of this, neutron dosimetry services employing nuclear emulsion film dosimeters covered 1,500 people at 65 organizations. During 1974 approximately 20,000 films were processed. Fifty organizations were required to have neutron dosimetry services based on the existing Atomic Energy Control regulations.

Nuclear emulsion film dosimetry covers a dose range from about 50 mrem to $8 \mathrm{rem}$. Pu-Be is used as a standard source. Most of the regular neutron exposures were in the range of 0-100 mrem. For criticality accident monitoring, activation detectors (e.g., In, S and $\mathrm{Au}$ ) are employed.

It is realized that the operation of the Neutron Dosimetry Service is time consuming because of mechanical scanning of tracks through a microscope TV arrangement and is prone to errors of several types. Because of these technical and scientific difficulties, this Bureau is continually reviewing new developments which will preferably automate neutron dosimetry services, improve the accuracy of neutron dosimetry measurements and be compatible with existing $x$, beta, gamma body dosimetry systems.

In this context, some preliminary work employing calcium sulphate (thutium) powder in rubber matrix has been carried out ${ }^{(1)}$ and reported. This study revealed possibilities and additional developmental work to increase the sensitivity is being considered.

\title{
Reference
}

1. Suitability of $\mathrm{CaSO}_{4}: \mathrm{Tm}_{\mathrm{m}}$ Systems for Occupational Dosimetry, paper presented at the Fourth International Conference on Luminescence Dosimetry, Krakow, Poland, August 1974. 
FAST NEUTRON DOSIMETRY AT ORNL

PROGRESS AND PROBLEMS*

\author{
Klaus Becker \\ Health Physics Division \\ Oak Ridge National Laboratory \\ Oak Ridge, Tennessee 37830
}

\title{
SUMMARY
}

Some of the results which have been obtained in this field since the last workshop of this type in Miami, 1973 are briefly summarized.

In track etching, the potentials and limitations of automatic spark counting have been further explored in three areas, namely the spark counting of recoil particle tracks (good efficiency is possible if the cellulose nitrate or polycarbonate foils are sufficiently overetched, but reproducibility and neutron energy response are less than desirable); determination of the precision and reproducibility of fission fragment spark counting under the point of view of developing mailable transfer dosimeters of sufficient precision $(\sigma<5 \%)$ in the $250-500$ rad range (it was shown that a reproducibility within $\pm 3-5$ percent is possible both with spark and visual counting); ${ }^{(2)}$ and feasibility of track spark counting in mica. (3) We found that the perforations created at the impact location of high-LET charged particles such as fission fragments in thin sheets of etched muscovite mica can also be conveniently evaluated by spark counting. Ancient fission tracks in the mica are annealed by an $800^{\circ} \mathrm{C}$ treatment. Mica offers advantages in certain applications as an inorganic detector which can be easily scanned by nonoptical means, because of the high thermal stability of the latent tracks $\left(>500^{\circ} \mathrm{C}\right)$ and excellent discrimination against low-LET particles.

In studies regarding the relationship between TSEE and TLD in $\mathrm{BeO}$, (4) it was found that the physical and chemical treatments affecting the

* Research sponsored by the Energy Research and Development Administration under contract with Union Carbide Corporation. 
sensitivity and stability of TSEE exert similar effects on the TLD performance. By measuring the TL in the UV, the lower detectable exposure limit is $21 \mathrm{mR}$. As the TL and TSEE peaks are well separated, the penetrating radiation component in a mixed field can, in principle, be evaluated by a TL (volume effect) measurement, followed by measuring the nonpenetrating, surface dose in the TSEE peak at a higher temperature. The accuracy in TSEE fast neutrons dosimetry has thus been improved because only a single detector, instead of the detector pair used in previous studies for discrimination between the gamma and neutron doses, is required. (5) There remain, however, problems with regards to the stability and reproducibility of TSEE dosimeters.

In agreement with current theories about trap saturation processes along charged particle tracks, an increase of the LET of radiation consistently produces a reduction in the TL response of conventional synthetic phosphors based on $\mathrm{LiF}, \mathrm{CaF}_{2}$, or $\mathrm{CaSO}_{4}$ as well as in some minerals. The alpha to gainma radiation response ratio on a rad/rad basis varies from phosphor to phosphor, and often from peak to peak in the same phosphor, usually between 0.05 and 0.5. There have, however, also been repeatedly claims by Russian researchers that some unusual TL materials based on metal sulfides are more sensitive for high-LET than for low-LET radiation, with obvious implications for fast neutron dosimetry. Tests have been carried out with Russian phosphor samples ( $\mathrm{ZnS}$; Na,Cu), and it was found that the dosimetric properties of such materials (sensitivity, stability, light response) do not make them desirable for routine dosimetry for the time being. Some other potentially interesting "new" approaches to the problem of solid-state fast neutron dosimetry, for example on the basis of lyoluminescence in organics, are also discussed. 


\section{References}

1. K. Becker and M. Abd-e1 Razek, ORNL-TM-4460 (1974), and Nuc1. Instr. Meth., in press.

2. K. Becker and J. S. Jun, Phys. Med. Biol., in press.

3. K. Becker, Nucl. Instr. Meth., in press.

4. R. B. Gammage and A. K. Garrison, Proceed. 4th Internat. Conf. Luminescence Dosimetry, Krakow, 1974.

5. R. B. Gammage, F. F. Haywood, M. H. Lee and J. S. Cheka, ORNL-TM-4624 (1974). 
LASL AUTOMATED PERSONNEL TLD SYSTEM TO BE SUPPLIED

BY HARSHAW CHEMICAL COMPANY

\author{
A. W. Blackstock \\ University of California \\ Los Alamos Scientific Laboratory \\ P. 0. Box 1663 \\ Los Alamos, NM 87545
}

\title{
SUMMARY
}

The automated TLD system includes 4-chip dosimeters, minimum nine digit identification (e.g., social security number), preheat and high throughput capability. The system is capable of limited interaction with and control by a computer.

The TL dosimeter consists of the rectangular dosimeters "card" and the card holder (badge). The material of the card is aluminum and the TLD chips are sealed in Teflon using no adhesive. One corner of the card is tapered to assure proper orientation both in the badge and the reader. Each card contains three TLD-700 and one TLD-600 chips. The TLD's are the standard Harshaw chips, $1 / 8$ inch $\times 1 / 8$ inch $\times 0.035$ inch. The replaceable ID label is placed across the card and provides both a visually and machine-readable nine digit number.

A final design of the card holder or badge has not yet been arrived at and it is not a part of the present contract. However, the preliminary design incorporates the albedo-neutron dosimeter designed by

Hankins, (1) modified to accept the TLD card. The TLD-600 chip and one TLD-700 chip are sandwiched between layers of polyethylene in the cadmium shield of the albedo-neutron dosimeter. The badge will contain a suitable filter over one of the remaining TLD-700 chips and an open window over the other. The dosimeter and badge combination will permit the monitoring of photon, beta and neutron doses.

The TLD card processing system consists of three basic components: (1) the mechanical transport module into which the cards are loaded, 
(2) the control and logic module which contains the logic and command structure for the operation of the transport module, and (3) the integrating picoammeter which integrates the $\mathrm{TL}$ output and presents it in digital form.

The transport module contains a large circular plate capable of being rotated through six equally-spaced positions (stations). The six stations in which the card can be positioned are auto load, station 2, unused in the LASL system, preheat, readout, auto unload and manual load/ unload. The large plate contains six smaller circular plates, corresponding to the six stations. These smaller plates carry the cards and also rotate to bring each TLD chip successively into the proper position.

A card cartridge is located over the load station. The card identification is made between station 1 and station 2 and the TLDs are subjected to a preheat of controllable temperature and duration at station 3 .

At station 4, the light output is measured with a PM tube in good optical coupling with the dosimeter. An in the case of the preheat, the temperature at the "read" hot finger is displayed on a meter. The temperature profile used to obtain the glow curve can be programmed.

At the auto unload station, the card is ejected upward into the receiving cartridge which is identical to the load cartridge. At the sixth station, a card may be manually inserted in or removed from the card carrier.

The Logic Module houses all logic circuitry, except for the digital output of the integrating picoammeter, and serves as the control and display center of the system. The basic electronic components of the logic are a microprocessor, programmable read-only memories (PROM's), random access memories (RAM's), and a variety of input-output subsystems. A 12-digit LED display is used to provide the operator with instrument status information. The information available on command includes I.D. of card at any station, program status and fault status. 
Certain program parameters will be stored in the logic module but may be modified from a keyboard or computer entry. Such parameters include temperature start and stop integrator, maximum temperature, preheat temperature, preheat time and read time. The current value of any parameter may be displayed on command.

A11 local operations are controlled from a panel located on the control module and all status information is displayed on this panel.

A permanent program for a representative cycle sequence and set of parameter values is stored in memory at time of manufacture and can be called by the NORM button. When PANEL MODE is activated, the program sequence and parameters may be set by controls on the panel. Up to six other stored programs may be recalled by buttons. Provision is made for stepping through a program.

The standard Harshaw Model 2000B integrating picoammeter, suitably modified to accept commands from the Logic Module, is used to integrate the current output of the phototube detecting the TL output of the detector.

The card cartridge has a capacity of 150 cards permitting $21 / 2$ hours of automatic operation at one card/min. The cartridge is keyed to permit insertion of cards only in the correct orientation.

Under normal operating conditions, the reader will, upon completion of card read operation, output the card I.D. and the TL readings of the card. The output wil1 be by means of the CCITT/EIA RS-232-C serial ASCII standard at a selectable baud of 110,300 or 1200 .

The reader system may be remotely controlled by commands through the EIA RS-232-C serial ASCII input.

Background and sensitivity checks and fault indications are provided. The present plan is to heat each TLD for 10 seconds and to accomplish the several moves in 2 seconds each. This should yield a cycle time of 50 seconds per card.

\section{Reference}

1. Dale E. Hankins, "A Sma11, Inexpensive Albedo-Neutron Dosimeter," Los Alamos Scientific Laboratory, Report LA-5261 (1973). 


\title{
NEUTRON DOSE MEASUREMENTS BY ELECTROLYTIC CONDUCTANCE \\ IN FISSION FRAGMENT DAMAGE TRACKS*
}

\author{
W. G. Cross and H. Ing \\ Atomic Energy of Canada Limited \\ Chalk River Nuclear Laboratories \\ Chalk River, Ontario, Canada KoJ lJo
}

The density of fission fragment damage tracks in a plastic foil exposed to neutrons against a radiator of fissionable material has been used for a number of years for determining neutron doses. Of the methods that have been developed for determining the number of tracks without having to count these under the microscope, spark counting appears to be the simplest and most accurate, providing that the track density is not too high. FIGURE 1 shows the proportionality between dose and number of sparks counted per $\mathrm{cm}^{2}$ when a Th radiator is used. At high track densities, overlap of the holes produced by sparks in the Al film leads to loss of counts. Ten rads is about the highest dose that can be counted with reasonable accuracy and this is 1 or 2 orders of magnitude smaller than might be received by someone exposed in a serious accident. While the sensitivity of such a dosimeter can be reduced by diluting the fissionable element in the radiator, two dosimeters would then be required to cover both low and high doses and this may not be convenient.

The very simple alternative method to be described here is intended primarily for higher track densities than can be measured by spark counting. It depends on filling the etched tracks that penetrate the foil with electrolyte and measuring the electrical conductance through them. This rather obvious method was tried over 10 years ago by walker, but was abandoned because it was not sufficiently reproducible. The essential problem is how reproducible the ratio of measured conductance to track density can be made. Since conductance depends on track diameters as well as on number of tracks,

* Presented at 19th Annual Meeting of Health Physics Society, Houston, TX, July 1974. These preliminary results should not be quoted without permission from the authors. 
one would expect that the etching process must be controlled more carefully than for methods sensitive only to the number of tracks.

FIGURE 2 shows the present version of the cell in which conductance measurements are made. It consists of two flat cylindrical volumes, each $2 \mathrm{~cm}$ in diameter and $1.6 \mathrm{~mm}$ thick, machined out of Lucite. The ends of the cell are covered with Pt electrodes whose surface has been converted to Pt black, as is standard practice for conductivity measurements. The two halves are clamped together, separated by the plastic foil and held with the electrodes in the vertical plane. The cell is filled with 0.1 normal $\mathrm{KCl}$ solution, through small holes, using a hypodermic needle. FIGURE 3 shows the appearance of the two halves of the cell.

The impedance between the Pt electrodes is measured with an A.C. bridge, at $1000 \mathrm{~Hz}$. Since the impedance of the cell contains a capacitive component, this is balanced by adjusting capacitance in the other arm of the bridge and the resistance across the cell is recorded. Measurements take between 1 and 2 minutes each.

The resistance through the foil can easily be calculated as shown in FIGURE 4. Here $R_{0}$, the electrolyte resistance with the foil removed, is about 10 ohms for our cell, $\bar{l}$ and $\bar{A}$ are the mean length and area of a track, $\rho$ is the resistivity of the electrolyte, and $n$ is the number of tracks.

The calculated resistance of a single hole etched to $1 \mu \mathrm{m}$ in radium is about 3 Megohms, which is easily measurable. This method is therefore capable of detecting a single track and so is just as sensitive as any other method of track counting. However, when the number of tracks is very sma11, any mechanical damage to the foil may produce a hole much larger than a single real track and thus produce a larger error than it would in a method that only counted the number of tracks.

The upper limit of measurable track densities will occur when the resistance through the holes in the foil is small compared with the resistance of the rest of the electrolyte, $R_{0}$. For this reason, the distance between the cell electrodes is made as small as convenient. For our cell, 
$3 \times 10^{5}$ holes $/ \mathrm{cm}^{2}$ have a calculated resistance of 3 ohms, compared with the cell resistance of 10 ohms. This would be about the upper limit for measuring tracks etched to $1 \mu \mathrm{m}$ in radius.

FIGURE 5 shows how the measured resistance through the foil varies with etching .time. Makrofol foils were exposed against Th radiators to equal fluxes of $14 \mathrm{MeV}$ neutrons, equivalent to about a $10 \mathrm{rad}$ dose and then etched for various times. One might expect that, after the etchant has penetrated the length of a track, the mean track diameters would then increase at a nearly constant rate. If this happens the conductance, which depends on the area of the holes, should be proportional to the square of the etching time. This behavior was found by Bean, et al., at G.E., for tracks in mica etched by hydrofluoric acid. In the slide, the straight line has a slope of -1 , corresponding to proportionality between $T^{2}$ and conductance. These data show that, even for etching times nearly 20 times shorter than are normally used for spark counting, the track diameters are proportional to etching time. Thus, the time for the etchant to penetrate the length of the track is a very small fraction of the total etching time.

FIGURE 6 shows the result of exposing foils against Th to various known doses of $14 \mathrm{MeV}$ neutrons. In this graph we have plotted conductance, rather than resistance, against dose. The absolute values are not particularly important since they apply only to our etching conditions, conductance cel1 and electrolyte. The slope of the straight line corresponds to proportionality between dose and conductance and the data shows that this proportionality exists for doses from 0.1 to about 1000 rads. These results were obtained using an etching time about half that normally used for spark counting. The maximum measurable dose, which corresponds to a resistance through the foil considerably smaller than that in the rest of the cell, could presumably be increased 10 times by reducing the etching time.

As mentioned earlier, the critical problem is the reproducibility of the resistance across a foil for a given dose. This depends on the reproducibility of etching, on the uniformity of the Makrofol foil and on ensuring that the tracks are completely filled with electrolyte for the 
resistance measurement--i.e., that no air bubbles are trapped in the holes. To check that the holes are filled reproducibly with electrolyte, foils whose resistance had been measured were washed and dried, put back in KC1 electrolyte and remeasured. Repeating this procedure a number of times gave resistances that reproduced within 2 percent. Thus, air bubbles in the tracks do not appear to be a problem.

As a test of overal1 reproducibility, 10 or 20 foils were all exposed to 10 rads of neutrons, given equal etching and their resistance measured. This was done several times and the standard deviations of the results were between 5 and 10 percent. To achieve this, we control the temperature of the etchant to $0.1{ }^{\circ} \mathrm{C}$, the specific gravity to 1 part in 1000 and are careful to keep the speed at which the etchant moves past the foil constant.

Occasionaliy a foil will have a resistance that exceeds the mean value for that dose by a large amount--as much as a factor of two. These foils can sometimes be brought into agreement by washing them in ultrasonically agitated water, suggesting that some holes have been blocked by loose debris from the etching process. On other occasions this treatment does not decrease the resistance significantly. Spark counts of such foils give a smaller number of holes than the mean value, but the difference is not nearly as great as the difference in resistance. These differences may arise from some change in the etching or from variation in the crystalline structure of the Makrofol.

To summarize the capabilities and limitations of the electrolytic conductance method of measuring track densities:

- the equipment is very simple and measurements can be made in 2 minutes

- the method is capable of determining fast-neutron doses between 0.1 rads and at least 1000 rads. While doses lower than 0.1 rads can be measured, the errors from possible mechanical damage of the foil make one hesitant to rely on measurements of very small doses. For doses less than a few rads, this method has no special advantages over spark counting, 
- the reproducibility obtainable is 10 percent or better but larger errors occur occasionally apparently because of variations in etching. Clearly it is necessary to understand and overcome these.

In addition to its use in determining track densities, conductance measurement, because of its ability to detect very small holes and its sensitivity to the amount of etching, provides a sensitive and convenient tool for studying the mechanism of track etching and the effects of variations in the etching technique.

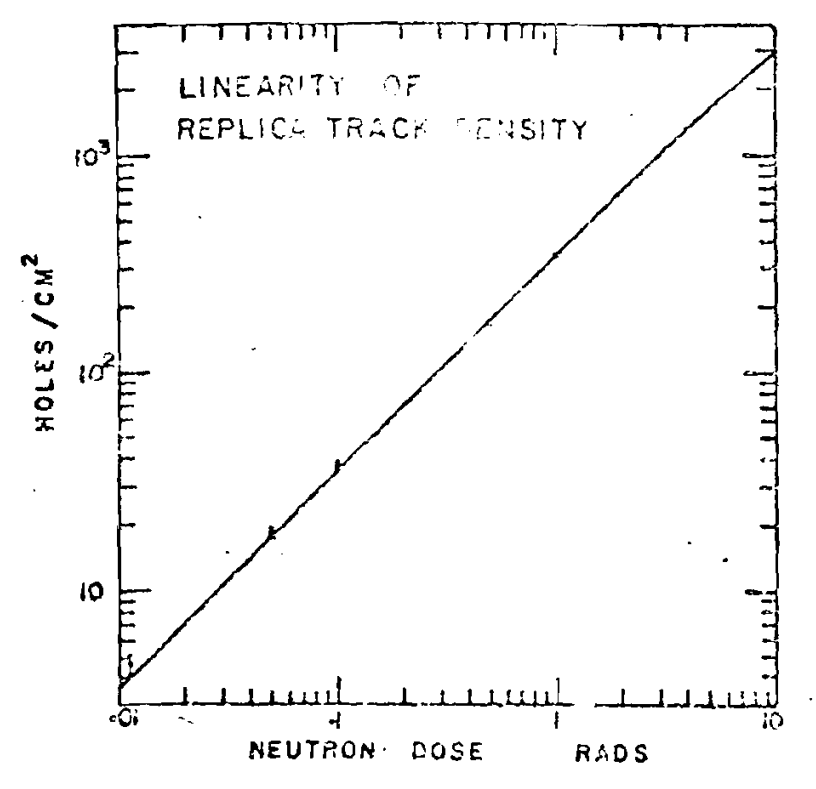

FIGURE 1. 


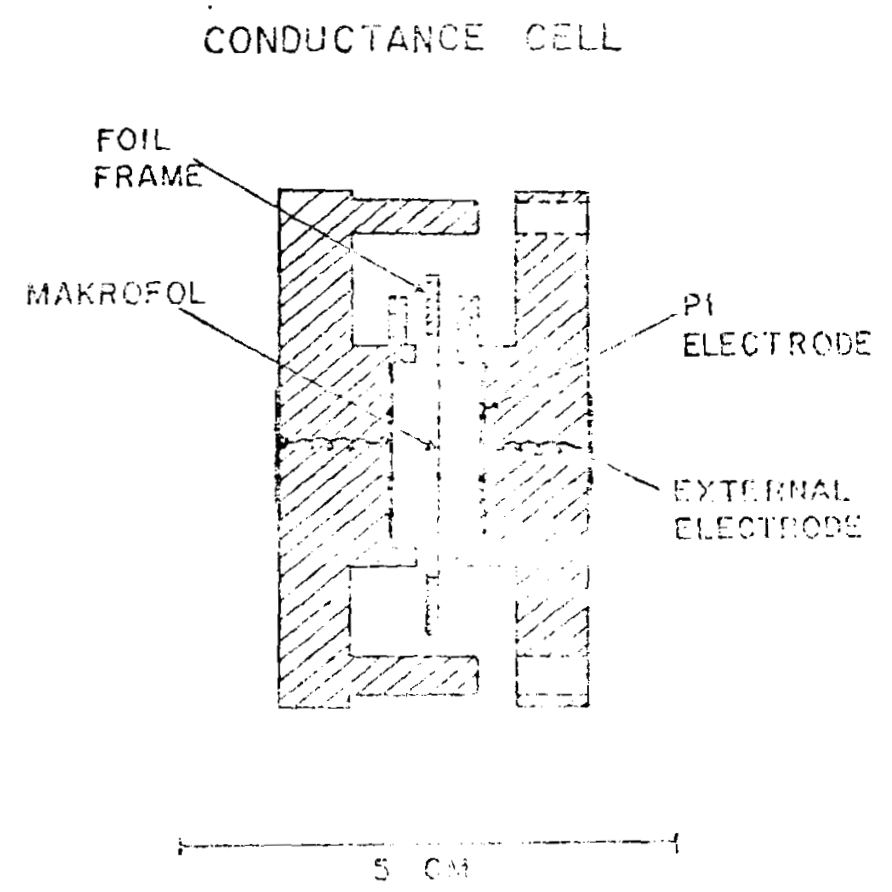

FIGURE 2.

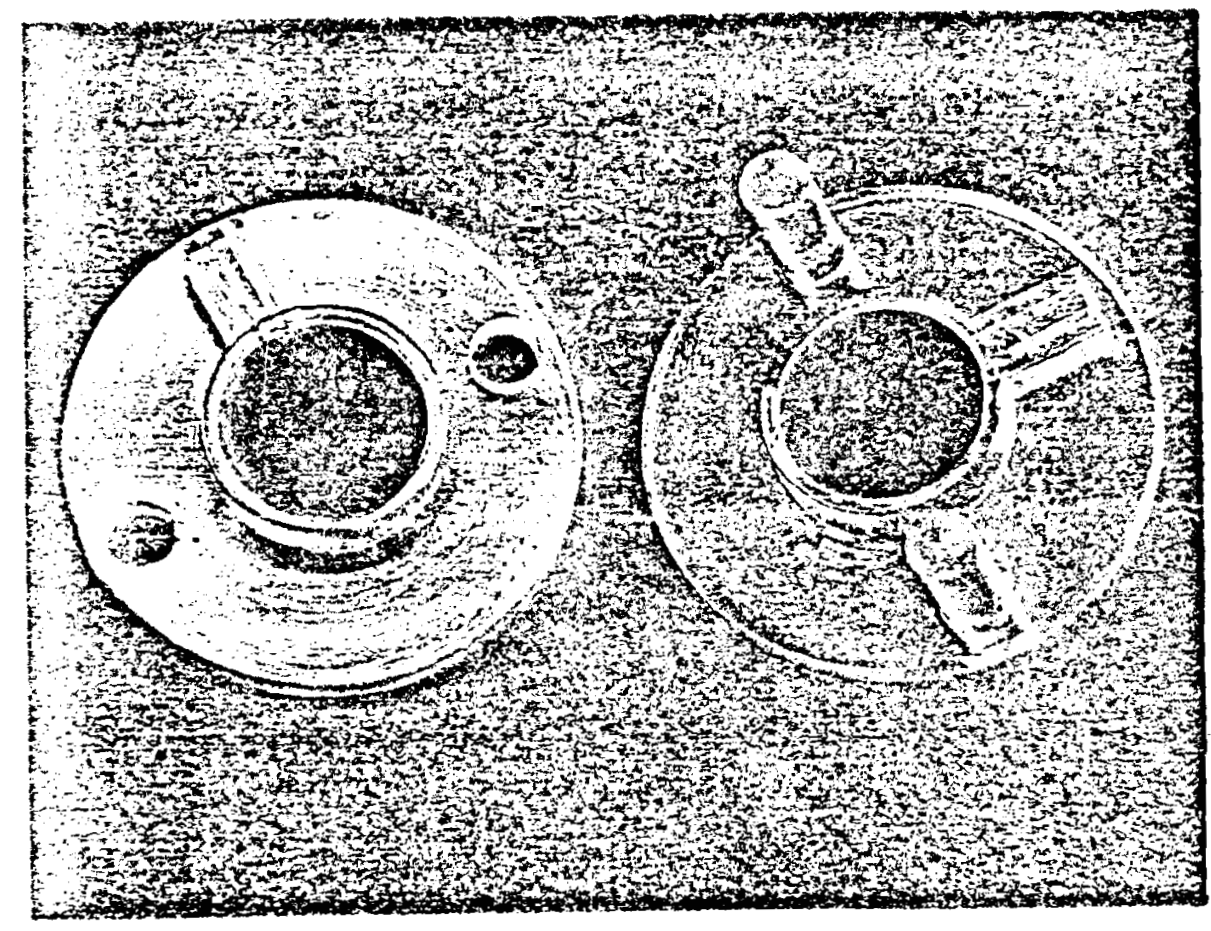

FIGUIRE 3. 
RESISTANCE THROUGH FOIL

$$
\begin{gathered}
\qquad R=R_{0}+\frac{1}{n}\left(\frac{\rho \bar{l}}{\bar{A}}\right) \\
R_{0}=\text { electrolyte resistance with foil removed }(i 10 \Omega) \\
\rho=\text { electrolyte resistivity }(78 \Omega-c m) \\
\bar{l}, \bar{A}=\text { mean length and area of a track } \\
n=\text { number of tracks }
\end{gathered}
$$

FIGURE 4.

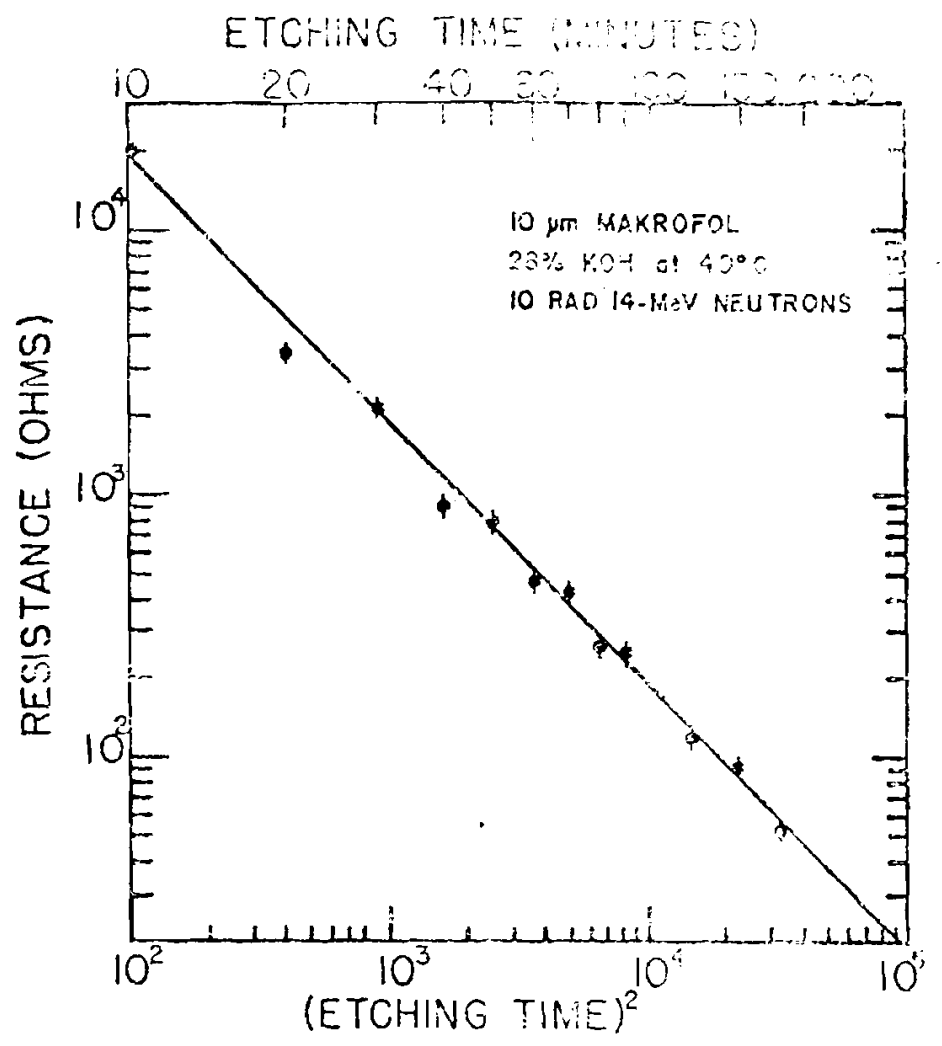

FIGURE 5. 


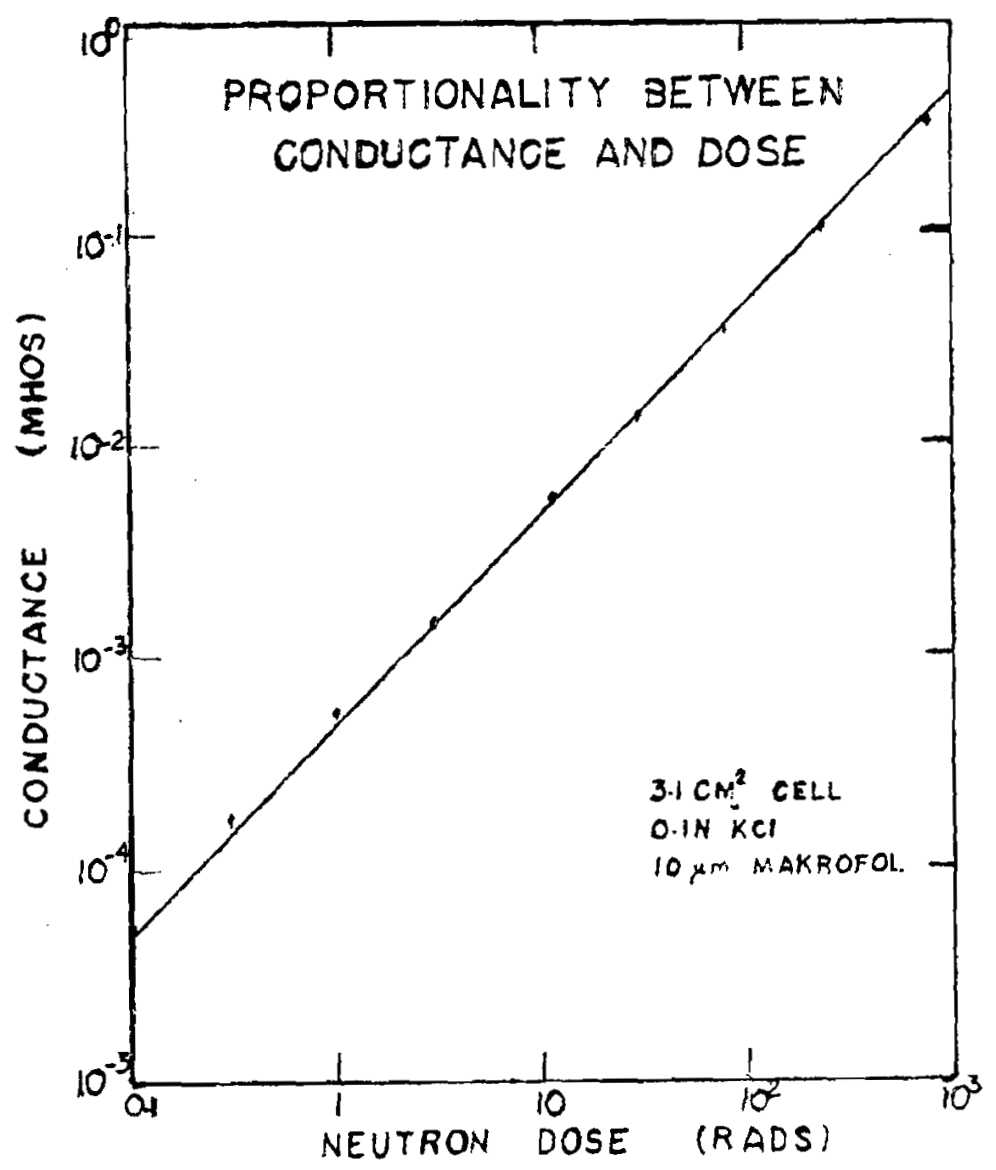

FIGURE 6. 


\title{
CALIBRATION OF THE EXPERIMENTAL BND PERSONNEL NEUTRON DOSIMETER FOR GENERAL USE
}

\author{
C. Distenfe]d \\ Brookhaven National Laboratory \\ Upton, NY 11973
}

I. The experimental Brookhaven neutron dosimeter, BND, was a composite damage track and thermoluminescent detector. Thorium fission was used to respond to $>1 \mathrm{MeV}$ and high sensitivity TLD 600 and 700 ribbons respond to softer neutrons. Previous experimental work* at the Alternating Gradient Synchrotron, AGS, a $33 \mathrm{GeV}$ proton accelerator, utilized the energy dependence of the ratio of thermoluminescent to Thorium response, softness. Softness variation was related to a correction factor used to adjust a TLD response to properly account for the dose equivalent.

An invitation was extended to participate in the 1974 Intercomparison of Personnel Neutron Dosimeters. The Oak Ridge National Laboratory study was similar to the standard nuclear accident dosimetry intercomparisons, but of lower dose magnitude. Neutron spectra of varying composition were generated by a $14 \mathrm{MeV}$ neutron generator and the HPRR reactor in its three configurations.

Participation in the study required the determination of different BND calibration constants for the much softer reactor spectra. The resulting study assumed that the high energy accelerator constants were properly specified. All remaining field spectra were assumed to be limited to $215 \mathrm{MeV}$. For this case, the thorium calibration value was $7.1 \mathrm{mrem}$. sparks $^{-1}$ and the problem was the interpretation of the TLD response.

\section{Thermoluminescent Response}

No known detector or series of detectors in BND or any other personnel neutron dosimeter has correct dose equivalent energy-dependence. Acceptable dosimeter performance can be achieved by calibrating any dosimeter to the

* C. Distenfeld, BNL 17452 (1972). 
exposure spectrum. A single exposure spectrum reflects few calibrations. The ambitious requirement to allow BND use for any spectra requires many spectra calibrations. This study was made manageable by computer simulation of BND response. The method required the energy dependence of TLD 600 to be folded with the known or assumed spectra producing BND values. The BND detector elements were compared to determine an energy dependent relationship for proper dose equivalent results.

TLD 600 consists of nearly pure ${ }^{6}$ LiF material. The most probable neutron interaction $(n, \alpha)$ occurs below a few electron volts.* Personnel exposures involve the impingement of neutrons on the hydrogen rich torso of man. The back scattered neutrons, albedo, are energetically organized in a continuum tailing to thermal energies. Thus, the Tl response was mainly due to albedo-neutrons from the wearers body and incident thermal-neutrons. Alsmiller** calculated the albedo-neutron fraction for neutrons of $<400 \mathrm{MeV}$ (Figure 1). Since $T \ell$ is a thermal-neutron detector, and the albedos calculated by $A l s m i l l e r$ cover the thermal region, a simple Tl energy relationship should exist, where TlP is the $\gamma$ equivalent neutron response.

$$
T \ell P=P N \emptyset(E) \sigma(E)
$$

Neglecting mass variations in the Tl ribbons and enlarging $P$ to include the constants, a $<0.4 \mathrm{eV}$ neutron $T \ell$ response $T \ell P(\mathrm{th})$ equivalent to $1.29 \mathrm{E}-4 \mathrm{mR}$ per unit fluence was measured. In general, the Tl response to neutrons of any other energy is:

$$
\operatorname{T\ell P}(a, b)=\operatorname{T\ell P}(t h) \cdot \frac{\int_{b}^{a} \sigma(E) d E}{\int_{4 \times 10^{-8}}^{10^{-8}} \sigma(E) d E}
$$

* Neutron Cross Sections, BNL 325.

$\star *$ R. G. Alsmiller, Jr., and J. Barish, ORNL-TM-3984 (1972). 


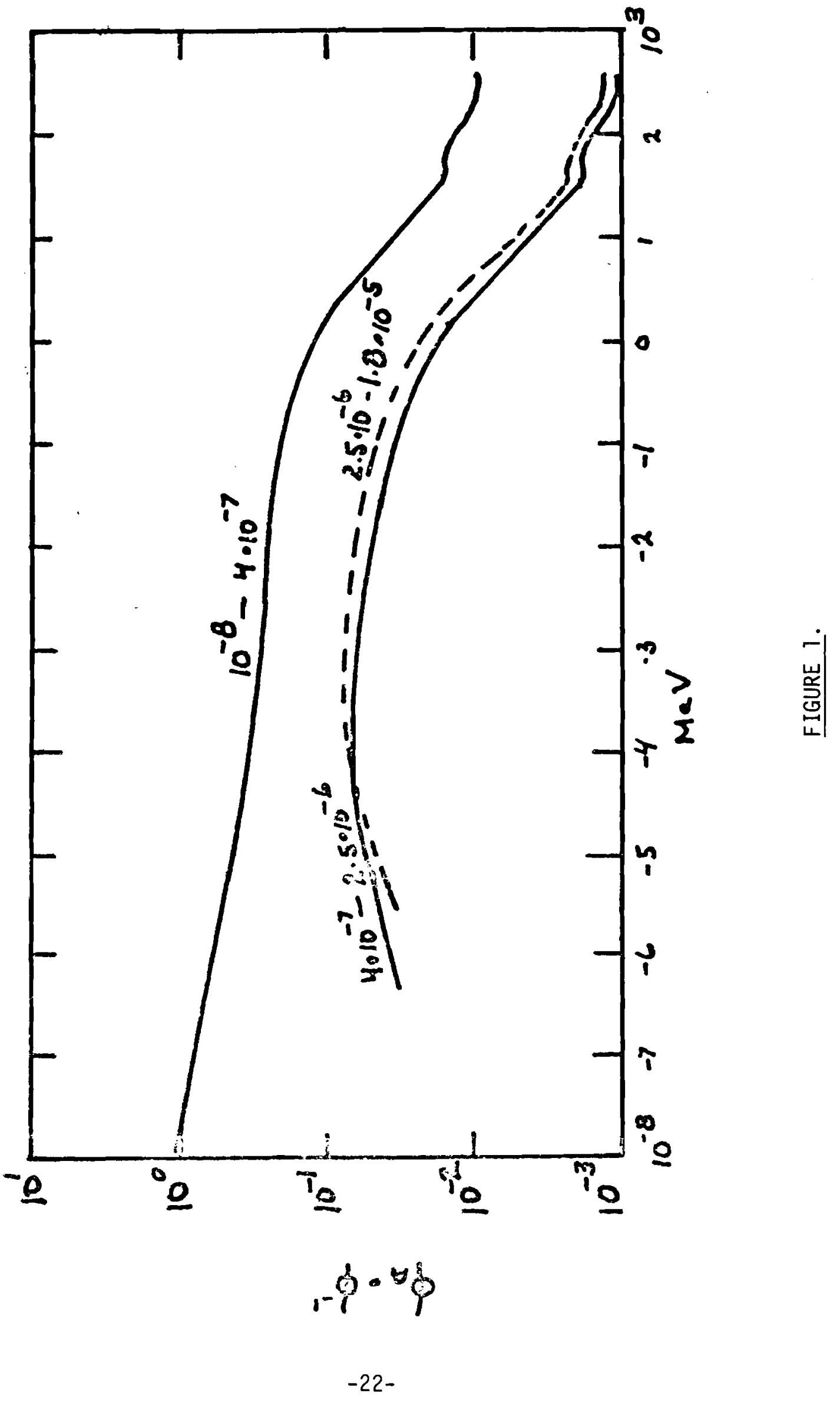


Three $T \ell$ configurations were investigated. The first consisted of the Tl 6 and 7 dosimeters shielded by plastic of $2200 \mathrm{mg} \mathrm{cm}^{-2}$. The presence of the plastic was ignored and the $T \ell$ was considered as unshielded, TlP.

Cadmi um, 0.03 inch, was used to alter the response. Tl material placed in front of the Cadmium was termed back cadmium, $B_{c d}$, and $T \ell$ located behind the Cadmium and termed front Cadmium, $\mathrm{F}_{\mathrm{cd}}$.

$T \ell$ response per unit incident $\emptyset$ of energy $E$ is given by:

$$
\begin{aligned}
T \ell P & =\emptyset(E) T \ell P(t h) \times \frac{\sigma(E)}{\sigma(t h)}+T \ell P_{1} \cdot \emptyset_{1}(E)+T \ell P_{2} \cdot \emptyset_{2}(E) \\
& +T \ell P_{3} \cdot \emptyset_{3}(E) \\
B_{C d} & =\emptyset(E) T \ell P(t h) \times \frac{\sigma(E)}{\sigma(t h)}+T \ell P_{2} \cdot \emptyset_{2}(E)+T \ell P_{3} \cdot \emptyset_{3}(E) \\
F_{C d} & =\emptyset(E) T \ell P(t h) \times \frac{\sigma(E)^{\star}}{\sigma(t h)}+T \ell P_{2} \cdot \emptyset_{2}(E)+T \ell P_{3} \cdot \emptyset_{3}(E)
\end{aligned}
$$

* $\mathrm{E}>4 \times 10^{-7} \mathrm{MeV}$

Where $\emptyset i(E) \equiv \frac{Q A(i, E)}{\emptyset(E)}$; $i$ relates to TlPi energy bands below and Figure 1 .

The $T \ell$ constants used were determined by Equation 2 and are:

$$
\begin{aligned}
& T \ell P_{1}=1.29 \mathrm{E}-4 \mathrm{mR} \mathrm{cm}{ }^{2} \cdot \mathrm{n}^{-1} ; \mathrm{E}-8 \text { to } 4 \mathrm{E}-7 \mathrm{MeV} \\
& T \ell P_{2}=1.01 \mathrm{E}-4 \mathrm{mR} \mathrm{cm}{ }^{2} \cdot \mathrm{n}^{-1} ; 4 \mathrm{E}-7 \text { to } 2.5 \mathrm{E}-6 \mathrm{MeV} \\
& T \ell P_{3}=0.49 \mathrm{E}-4 \mathrm{mR} \mathrm{cm}{ }^{2} \cdot \mathrm{n}^{-1} ; 2.5 \mathrm{E}-6 \text { to } 1.6 \mathrm{E}-5 \mathrm{MeV}
\end{aligned}
$$


The three functions (Figure 2) have some relative energy dependence. $F_{c d}$ is significantly different than the $T \ell$ paid in the thermal region so the integral difference for broad spectra occurs in the thermal region. It is clear that the T\&P and $B_{C d}$ relationship affords the best chance to develop a $T \&$ correction system.

The value of the computer simulations depends on the quality of the response functions. This was evaluated by comparing six measured cases with the corresponding calculated values (Figure 3 ). Five parameters per case were considered and all seemed to be in reasonable agreement with the calculated values.

\section{Test Spectra}

Seventeen hypothetical spectra were generated using the HPRR lucite shielded spectrum as a starting point. One softer and fifteen harder spectra were composed (Figure 4). The hypothetical group was used to calculate the BND constants. The softness relationship, TeP.sparks ${ }^{-1} k_{1}$ was evaluated as follows:

$$
\text { TlP } \cdot \mathrm{mrem}^{-1}=k_{1}=\frac{T \ell P}{\text { MADE }}+7.1 \times \text { sparks }
$$

The hypothetical spectra produced the relationship, $k_{1}$, illustrated in Figure 5, and used for the ORNL intercompriso:, measurements. Results indicated that the Thorium and unshielded $T \ell$ pair elements indicated the unshielded HPRR dose equivalent to +5 percent, steel shielded to -44 percent and the lucite shielded core to +50 percent. Softness ratios of $>10$ reflect a strongly diminishing spark response. Monoenergenic neutron fields of $<1 \mathrm{MeV}$ afford zero thorium response, erroneously suggesting a soft spectrum. Additional1y the 44 percent agreement (56 percent in error) for the steel shielded HPRR spectrum should be improved. For the above reasons other energy depend relationships were needed. 


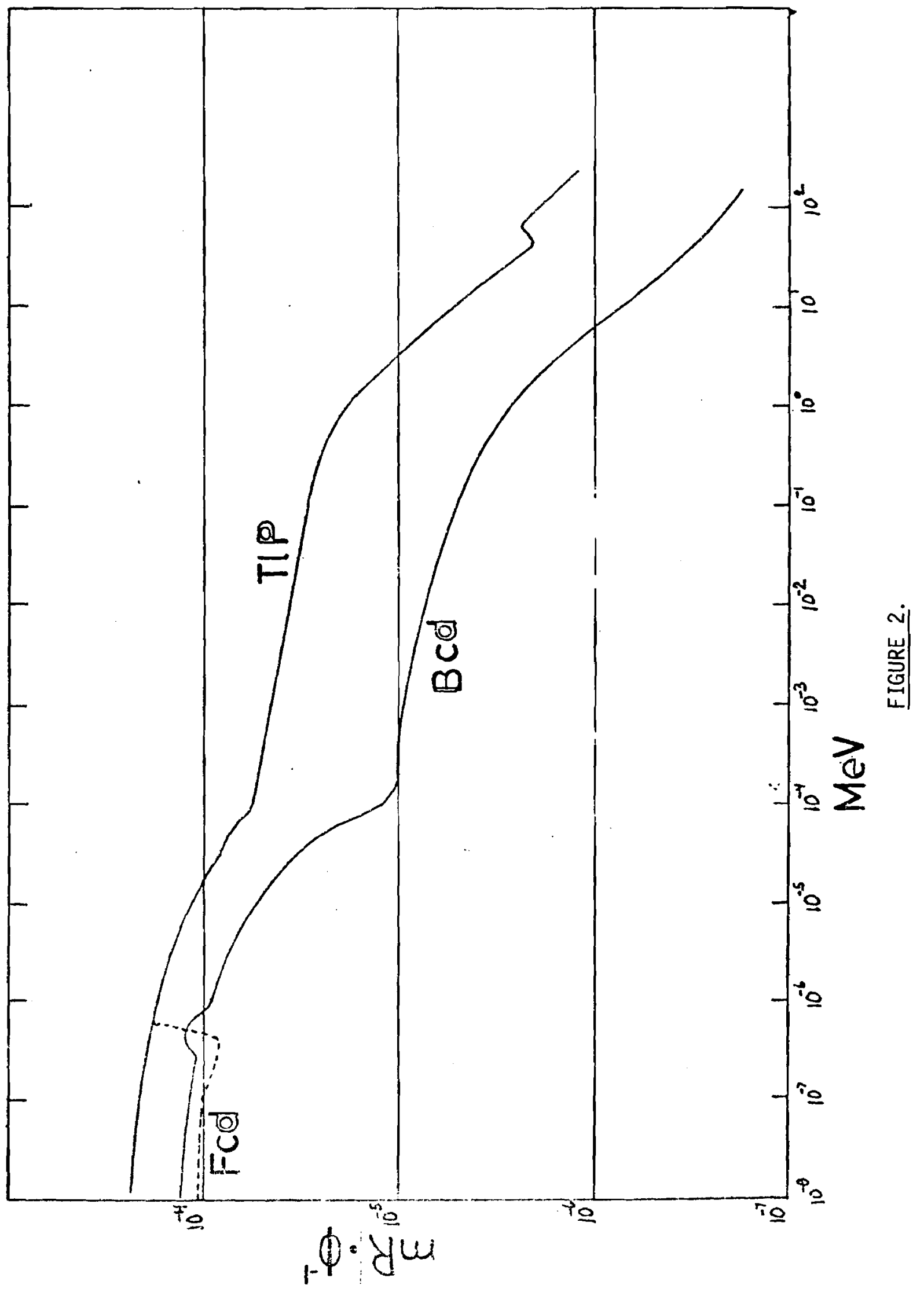




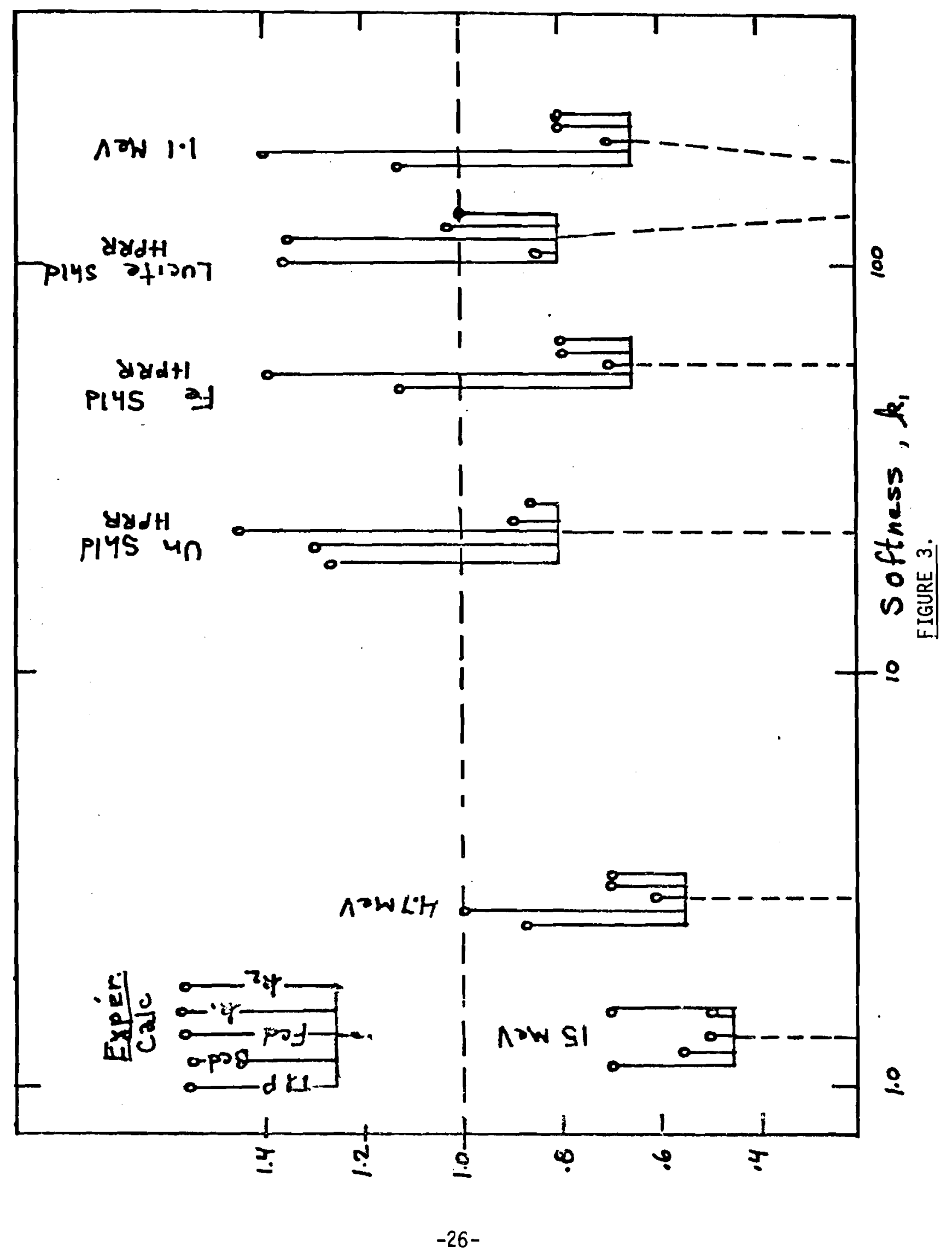




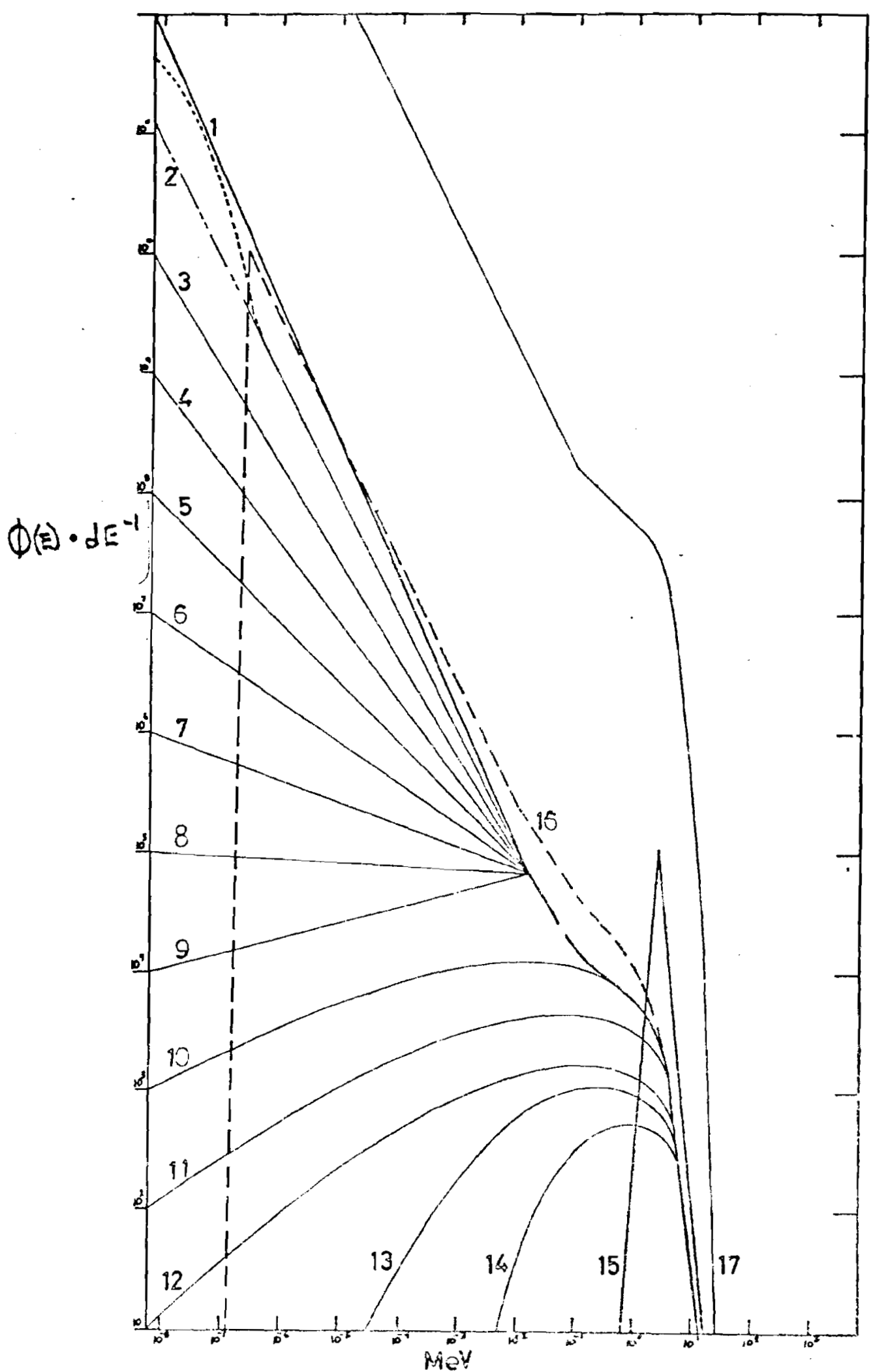

FIGURE 4.

$-27-$ 


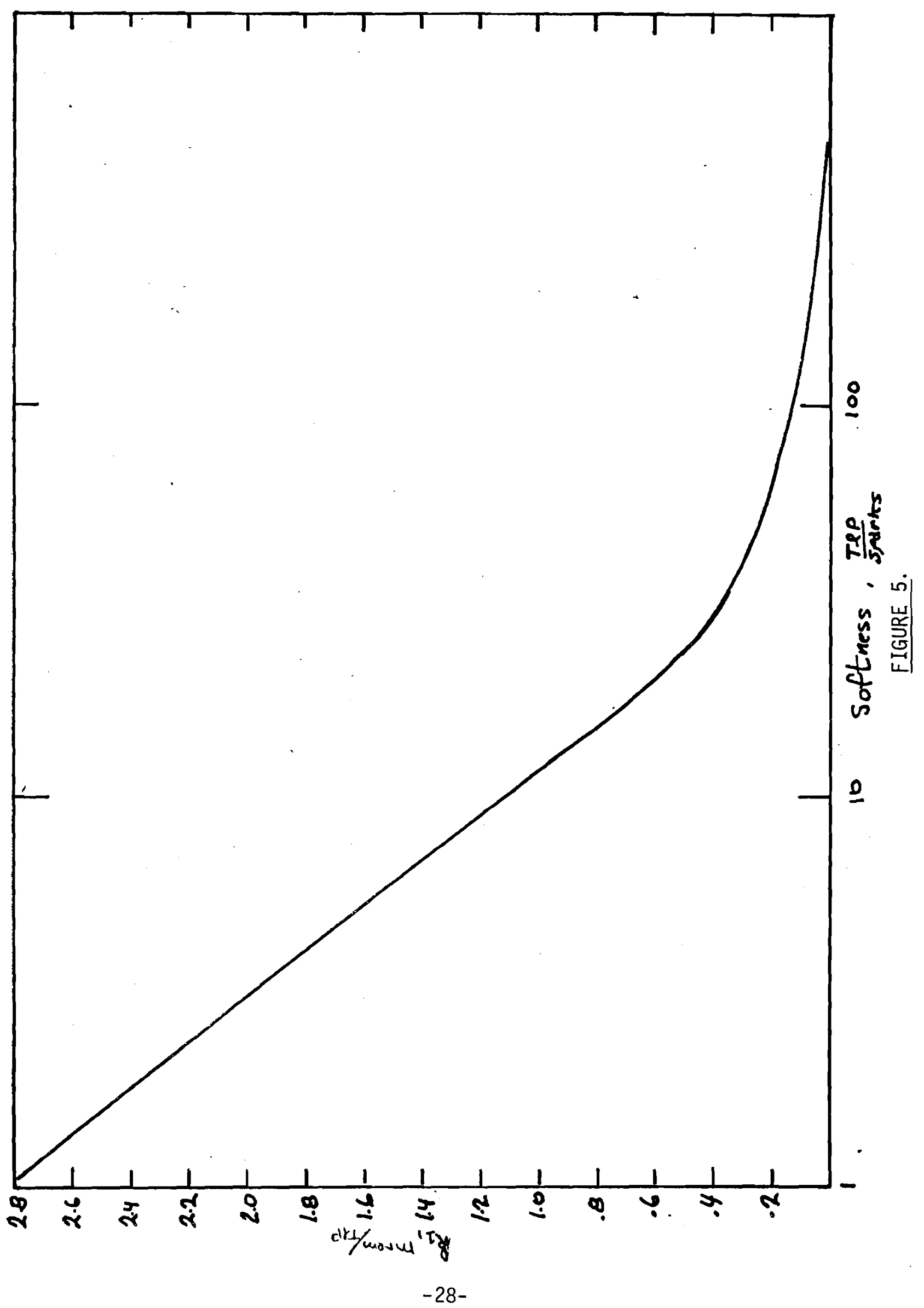


Considering the quantities available, the $B_{c d}$ element favors the thermal portion of the incidence spectra, while the TlP gains added response from the albedo $T_{\ell} P_{1}$ (Equation 3 ).

Clearly the quotient of $B_{C d}$ to TeP is a softness like relationship (Figure 6). The $B_{C d} \cdot T \ell P^{-1}$ values were multiplied by 100 and are seen to conform with $k$, values $>16$. A trial composite response was constructed that used $k_{1}$ correction values for softness values $\lesssim 16$, and $B_{c d}(100) \cdot T \ell P$, $k_{2}$, correction values for softness values $>16$.

IV. Results

Preliminary results are given for eight real spectra and the 17 hypothetical spectra (Figure 7). Results of all the real spectra measurements except $\mathrm{Californium,} \mathrm{were} \mathrm{determined} \mathrm{with} \mathrm{BND} \mathrm{badges} \mathrm{incorporating}$ $B_{c d}$ and $F_{c d}$ elements. The ratios of the BND derived dose equivalent to the true value is designated by letter $E$. The calculated BND elements similarly interpreted are designated by letter $C$. Results for the hypothetical spectra are good as expected, and the measured BND to known dose equivalent values are improved over work with single constant, $k_{1}$. 


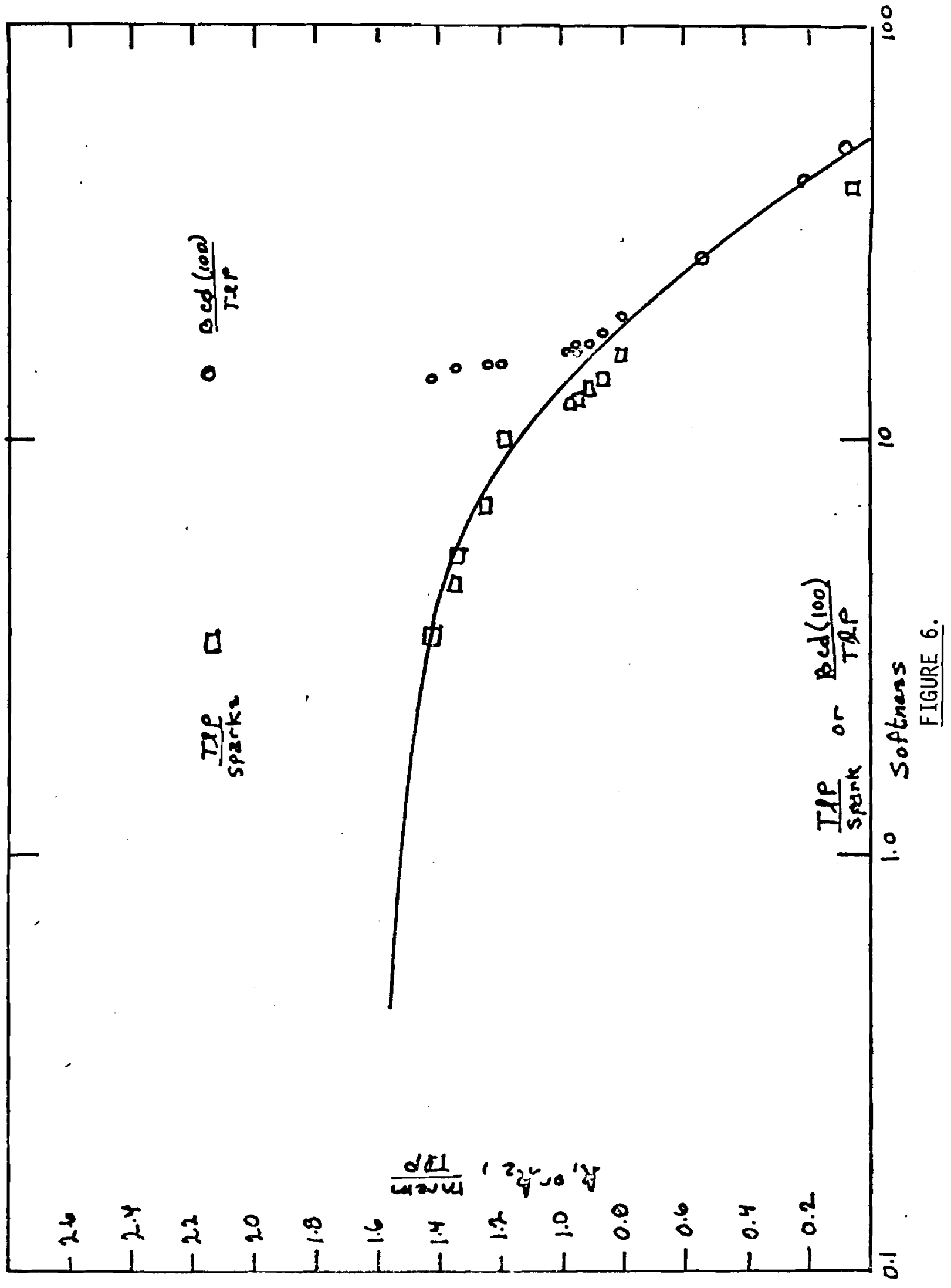




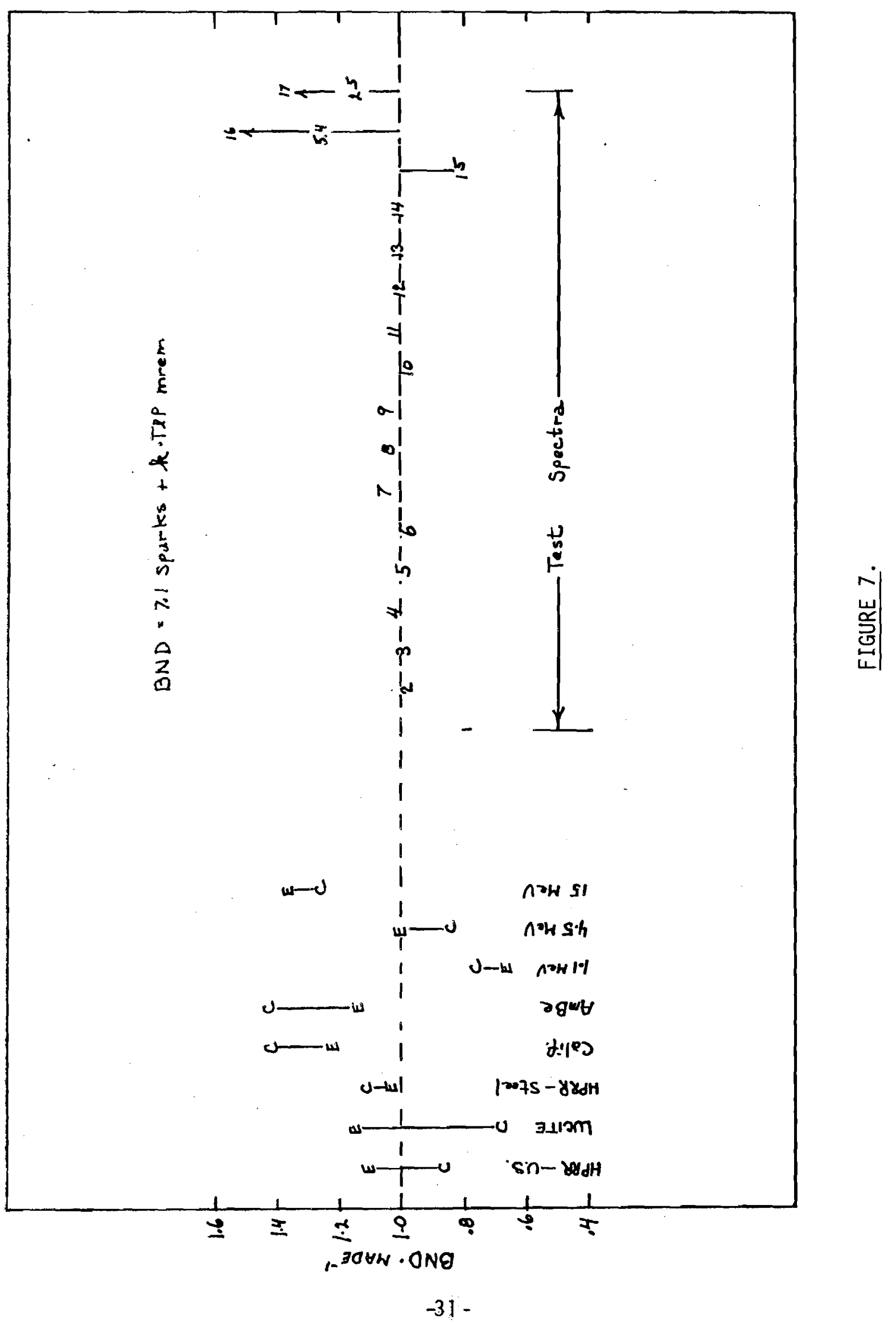




\section{FAST NEUTRON DOSIMETRY USING HIGH TEMPERATURE PEAKS \\ IN LiF AND $\mathrm{CaF}_{2}: \mathrm{Tm}$}

G. W. R. Endres

Battelle Memorial Institute

Pacific Northwest Laboratory

Richland, Washington 99352

\section{SUMMARY}

Lithium fluoride has been used for a number of years in routine personnel dosimetry for beta-gamma radiation and for neutron dosimetry at some laboratories utilizing the albedo technique. For most dosimetry purposes, the glow peaks at about $200^{\circ} \mathrm{C}$ are most convenient. Consequentiy, the higher temperature peaks have not been investigated to any great degree to determine their responses to various types of radiations. Peaks occur in Lif at about $260^{\circ} \mathrm{C}$ and about $320^{\circ} \mathrm{C}$. The ratio of the $260^{\circ} \mathrm{C}$ peak height to the $200^{\circ} \mathrm{C}$ peak height is about 0.03 . The $320^{\circ} \mathrm{C}$ peak has, for the experiments we have conducted, given rather inconclusive results and has not received further study. The data presented for Lif were taken only from the $200^{\circ} \mathrm{C}$ and $260^{\circ} \mathrm{C}$ peaks.

We have found for lithium fluoride that these two peaks can be more effectively separated by using bulb dosimeters and reading them out in a peak reading instrument. In this readout mode, the glow curve is separated into several parts and the $200^{\circ} \mathrm{C}$ and $260^{\circ} \mathrm{C}$ peaks are easy to identify. For neutron dosimetry, the ratio of the $260^{\circ} \mathrm{C}$ peak to the $200^{\circ} \mathrm{C}$ peak is a function of neutron dose. Thus, this technique provides the possibility for making both neutron and gamma measurements at the same time and with the same dosimeters.

A new phosphor, $\mathrm{CaF}_{2}: \mathrm{Tm}$, also shows promise of being useful for simultaneous neutron and gamma measurements. It does not have a tissue equivalent response for photon radiation but could be filtered to give a useful response above $50 \mathrm{keV}$. A typical glow curve for $\mathrm{CaF}_{2}: \mathrm{Tm}$ (TLD-300) is double with one peak about $150^{\circ} \mathrm{C}$ and the other peak about $240^{\circ} \mathrm{C}$. 
Separation of these peaks is much better than the $200^{\circ} \mathrm{C}$ and $260^{\circ} \mathrm{C}$ peaks in Lif. In $\mathrm{CaF}_{2}: \mathrm{Tm}$ the peak at $240^{\circ} \mathrm{C}$ appears to be sensitive to fast neutrons in a way similar to LiF (TLD-700). For TLD-300 the peak at $150^{\circ} \mathrm{C}$ is very insensitive to both thermal and fast neutrons though this peak does exhibit some fading at room temperature.

In both $\mathrm{LiF}$ and $\mathrm{CaF}_{2}: T m$ the response to fast neutrons appears to be due to scattering interactions which transfer energy to the higher temperature traps. The measurements of fast neutrons by this technique does not require that the dosimeters be backed by a phantom. Measurements with cadmium covered dosimeters have shown that the response is a direct fast neutron response. Measurement of the energy response of this phenomenon with the LiF bulb dosimeters also indicates that the response is due to a scattering type interaction. The response as a function of neutron energy increases as average neutron energy increases for exposures to ${ }^{252} \mathrm{Cf}$, AmBe and $15 \mathrm{MeV}$ neutrons.

Measurements with $\mathrm{CaF}_{2}: \mathrm{Tm}$ have developed very we11. Because of the room temperature fading of the $150^{\circ} \mathrm{C}$ glow peak, $\mathrm{CaF}_{2}: \mathrm{Mn}$ is used in combination with $\mathrm{CaF}_{2}: \mathrm{Tm}_{\mathrm{T}}$ to measure the gamma component of the radiation field. With this system the detection 1 imit for fast neutrons from ${ }^{252} \mathrm{Cf}$ is less than 100 mrads when using the $0.32 \times 0.32 \times 0.038 \mathrm{~cm}$ blocks of TL material. Measurements with $\mathrm{CaF}_{2}: \mathrm{Tm}$ bulbs have just begun and they appear to be as much as 40 times more sensitive than the sma 11 blocks. They a 750 have 10 times as much phosphor in them. It is hoped that within the next year or so a technique can be developed which will increase the system sensitivity enough to make a practical personnel neutron dosimeter.

A Harshaw model 2000 system was used for readout of the LiF and $\mathrm{CaF}_{2}: \mathrm{Tm}$ blocks of various sizes. A Harshaw peak reading system was used for reading the bulb dosimeters. The peak reading system can be sequenced through several cycles without cooling to read out the various peaks. To obtain glow curves a recorder was connected with its $X$-axis to the temperature output of the reader and its $Y$-axis to the photomultiplier current output. Two different sizes of Lif dosimeter blocks were used: 
$0.32 \times 0.32 \times 0.089 \mathrm{~cm}$ and $0.64 \times 0.64 \times 0.086 \mathrm{~cm}$. The $\mathrm{CaF}_{2}: \mathrm{Tm}$ blocks were $0.32 \times 0.32 \times 0.038 \mathrm{~cm}$ thick. The bulb dosimeters had approximately $90 \mathrm{mg}$ of phosphor fixed to the center heater. 
SCATTERING CORRECTION FOR NEUTRON DETECTOR CALIBRATION

\author{
Ferenc Hajnal and James E. McLaughl in \\ Health and Safety Laboratory \\ U.S. Energy Research and Development Administration \\ New York, New York 10001
}

Shielding and operational health physics measurement often necessitate the determination of doses and dose rates from scattered as well as primary neutrons from distant, extended sources. The composition of the stray neutron field is influenced by the geometry and distribution of the sources, shielding material and objects in or near the line-of-sight of the sourcedetector configuration. Because the effect of scattering is complex, the description of the neutron field or neutron flux with simple mathematical formulas is difficult. Ideally, the field can be studied and characterized by measurements taken with neutron detectors, whose energy responses are known. Actually, calibration laboratories often simulate a scatteringfree environment by performing detector calibrations on elevated platforms away from scattering objects.

It is still necessary to understand the role of scattering on both the calibration and field measurements and correctly compensate for it. Moderated-neutron detectors continue to be used for such measurements. Calibrations are usually made with $\alpha, n$ or ${ }^{252} \mathrm{Cf}$ point sources, or neutron beams of known energies and intensities, in relatively low scatter geometries. Our attempt to quantitate scattering contributions during calibration was based on the DePhanger and Nichols constant scattering contribution formula (BNWL-260, 1960), relating to the counting rates from point sources, which has the form,

$$
A(x)=a+\frac{b}{(x+c)^{2}}
$$

We modified this expression by introducing a variable scattering term to obtain, 


$$
A(x)=\frac{a^{-} e^{-k_{0}}\left(x+c^{\prime}\right)}{\left(x+c^{\prime}\right)}+\frac{b^{-} e^{-\sum_{t}\left(x+c^{\prime}\right)}}{\left(x+c^{\prime}\right)^{2}}
$$

In both equations the first terms on the right account for scattering and the second represent the source terms; $x$ is the source-to-detector distance, $c$ or $c^{\prime}$ represent the location of the effective center of the detector, and $k_{0}$ is equal to $0.55 \sum_{t}$ (Lindenbaum, 1957). Detector sensitivity $S$ is determined from the characteristic constants $b$ or $b^{-}$by way of

$$
b=\frac{Q(t) \varepsilon\left(90^{\circ}\right) S}{4^{\pi}}
$$

where $Q(t)$ is the source field and $\varepsilon\left(90^{\circ}\right)$ is the source anisotropy factor.

A detailed description of these equations is given in pages 445-449 in Topics in Radiation Dosimetry, Supplement 1, edited by F. H. ATTIX (Academic Press 1972, New York). We applied Equations 1 and 2 to Precision Long Counter and Bonner sphere measurements of ${ }^{239} \mathrm{PuBe}$ and ${ }^{252} \mathrm{Cf}$ neutron sources.

Percentage scattering curves and data comparing the measured and calculated sensitivities of the different detectors in [(counts per minute) $\left.\left(\mathrm{n} / \mathrm{cm}^{2} \mathrm{~s}\right)\right]$ were developed based on measurements in both a high-scattering room and in a very low scattering environment. (For some of the data, see HASL-222.) The percentage scattering contribution is negligible at small distances for the Precision Long Counter and the large moderator spheres. The scattering contribution can be as 1 arge as 40 to 50 percent for smaller detectors and bare ${ }^{6} \mathrm{LiF}(\mathrm{Eu})$ scintillator detectors that are exposed to ${ }^{239}$ PuBe sources in a medium-size room at a $150-\mathrm{cm}$ source-to-detector distance.

The reproducibility of the measurements is very good, better than three percent, in a 6 month period. The accuracy needs to be estimated by using ${ }^{239}$ PuBe and ${ }^{252} \mathrm{Cf}$ source measurements and published spectra data, 
and by comparing those made at other laboratories. This is difficult because few specifics on the exact size and weight (that is, density) of the spherical detectors are identified.

The response function of most of the detectors is, of course, far from flat, so if single detectors are used to determine the neutron dose, one has to be reasonably sure that field and calibration source spectra are similar. 


\title{
LLL SPECIAL PROJECTS DIVISION RESEARCH IN NEUTRON MEASUREMENTS TECHNIQUES*
}

\author{
Richard V. Griffith, Dennis R. Slaughter and Thomas R. Crites \\ University of California \\ Lawrence Livermore Laboratory \\ Livermore, California 94550
}

The neutron measurement work done in this division is primarily in support of the applied health physics program at LLL. Currently the emphasis is on neutron spectrometry and personnel neutron dosimetry.

The spectrometry development is being done to provide spectral measurements of the source-moderator configurations used in our calibration facility. These measurements will be used for studies of dosimeter energy response. In the long run, we intend to assemble a system that can be used for high resolution spectrum measurements at the Laboratory's neutron generation facilities. This information will be used to provide data for neutron shielding problems.

Our spectrometry work includes development of sophisticated, high resolution detector systems as well as refinement of the conventional multisphere moderator techniques. High resolution detectors under study include NE 213 scintillators, ${ }^{6}$ LiI scintillators, ${ }^{3}$ He proportional counters and hyd ogen proportional counters. The development primarily involves selecting a small set of detectors capable of spectral measurements from $10 \mathrm{keV}$ to $20 \mathrm{MeV}$, refinement of pulse height analysis electronics for use with these detectors, and development of response function unfolding techniques which can be applied to the assembled system.

The effort on multisphere detectors has been to provide an array that can be used now to make "field" measurements and will be available after the development of the high resolution systems to provide spectral information below $10 \mathrm{keV}$. We are currently using a set of polyethylene

* Work performed under the auspices of the U.S. Energy Research and Development Administration. 
spheres with a $1.27 \mathrm{~cm} \times 1.27 \mathrm{~cm}{ }^{6}$ LiI detector on loan to LLL from the ERDA Health and Safety Laboratory. The system has been used to make neutron spectrum measurements both in the calibration facility and in working areas. A prototype of a new portable pulse height analyzer is used for most field mea surements.

The data is processed with the LOUHI computer code developed at the Lawrence Berkeley Laboratory. (1) The code is capable of unfolding neutron spectra from activation foil measurements with threshold detectors, moderating spheres, and nuclear emulsions.

One interesting aspect of the LOUHI code is that the responses of a detector to "known" spectra can be used by LOUHI to estimate the response function of that detector. That is, if the roles of the spectra and response function are reversed and spectra are provided as input data, the code solves the activation equation for the detector responses. This, of course, requires the availability of a number of different neutron spectra. Our calibration facility has available ${ }^{238}$ PuBe and ${ }^{252} \mathrm{Cf}$ sources which can be used under ten different moderation' conditions. We are beginning measurements with these sources and the LOUHI code to estimate the responses to moderated neutron detectors such as, TLD albedo dosimeters.

The problem of low level neutron spectrometry in pulsed or otherwise varying fields has led to interest in use of a multisphere system using track registration detectors so the spheres can be exposed simultaneousiy. Our current-studies are being done with ${ }^{235} U$ fission foils and thin films of polycarbonate for spark counting. The immediate problem is establishment of response functions for the various moderators. This will be done by combination of computer calculations using a discrete ordinates code, experimental measurements with monoenergetic neutrons from $10 \mathrm{keV}$ to $20 \mathrm{MeV}$ using LLL accelerators, and LOUHI calculations with our calibration facility measurements. We expect to be able to yield useful spectra at levels of 1 to 5 mrem over exposures of many days.

We are still concerned with the problem of developing a dependable, sensitive and accurate personnel dosimetry system. Our studies involve 
development of an albedo dosimeter with improved spectral response characteristics and fast neutron dosimeter which could be used to augment albedo dosimeter data for improved accuracy at dose equivalents in excess of a few hundred mRem.

Several variations, using different shield materials, of albedo badges have been examined in an effort to gain dose equivalence information independent of information concerning the incident neutron spectrum. Recent work has concentrated on defining the energy dependence of a simple albedo type dosimeter (TLD-600, 700 pairs on either side of a borated plastic shield) to the variety of source/moderator configurations available at LLL and reported at the last work shop. Preliminary results indicate a predictable energy dependence can be defined with a given source/moderator combination. Information yielded from the badge is sufficient to determine a calibration factor for a wide range of moderator thicknesses in this case. However, when the initial source or moderator type is changed, then determination of the calibration factor is no longer simple.

There are three potentially useful track registration techniques currently under investigation as fast neutron dosimeters. None of these involve the use of fissionable material.

1. Electro-chemical Etching - In 1970, L. Tommasino (2) reported the use of an alternating electric field current applied across a dielectric during etching to enhance the visibility of tracks from fission fragments and alpha particles. A recent report extended this work to neutron recoil tracks. (3) We have attempted to reproduce these results, however, the unexposed background we have found in various samples of polycarbonate films with thicknesses of $0.013 \mathrm{~cm}$ to $0.038 \mathrm{~cm}$ has been equivalent to a few rem. Annealing overnight at $160^{\circ} \mathrm{C}$ does not reduce the background level significantly. Although the recoil tracks are enhanced as suggested, the technique could not be used without a method of reducing the background significantly. 
2. In 1972 , a report was made at the International Conference on Nuclear Photography and Solid State Track Detectors, ${ }^{(4)}$ suggesting the use of $\mathrm{AgCl}$ single crystals for neutron dosimetry. Dr. Charles Childs at the University of North Carolina has been working with silver halide crystals for heavy ion detection in applications such as cosmic ray studies. His technique involves decoration of the tracks by simultaneous application of electric field and U.V. light. The photoelectrons produced combine with silver ions along the particle track to produce free silver which provides a visible track.

We have exposed $\mathrm{AgCl}$ crystals doped with different materials to 30 rem of ${ }^{252} \mathrm{Cf}$ neutrons. The crystals were returned to $\mathrm{Dr}$. Childs for "decoration." He reports no visible tracks in $\mathrm{Pb}$ doped crystals, but there appear to be tracks in crystals doped with other materials. The crystals have not yet been returned to us, so we cannot make more definite comments.

3. LR 115 - We have been working with the commercial cellulose nitrate, $L R 115,{ }^{(5)}$ for sometime. The material uses a $0.001 \mathrm{~cm}$ thick layer of red dyed cellulose nitrate as a particle detector. Holes in the red layer after etching are very visible in a microscope when viewed with green light.

Currently, we are investigating the use of tracks from direct interaction in the film as well as a Be radiator as suggested by Frank and Benton. ${ }^{(6)}$ The light Be recoils are more efficient for track production than the $\mathrm{C}, \mathrm{N}$, and $\mathrm{O}$ in the cellulose nitrate at fission neutron energies. Because tracks from Be recoils are apt to be seen at lower energies than those from direct recoils, we may be able to obtain some estimate of the neutron spectral quality using data from films with and without Be radiators together with the low and intermediate energy albedo detectors. 
There are certainly other potentially useful track registration techniques, such as spark counting of direct recoils in thin films, but we have selected those that seemed most promising to fill our current needs.

\section{References}

1. J. T. Routti, "Mathematical Considerations of Determining Neutron Spectra from Activation Measurements," Proc. Second Intern. Symp. on Accelerator Dosimetry and Experience, Stanford University, November 5-7, 1969, paper CONF 691101.

2. L. Tommasino, CNEN Report RT/PROT (71), 1, 1970.

3. M. Sohrabi, "The Amplification of Recoil Particle Tracks in Polymers and its Application in Fast Neutron Personnel Dosimetry," Health Physics, 27, 6, pp. 598-600, 1974.

4. G. Heniz, et al., "Radiobiological and Dosimetric Applications of $\mathrm{AgCl}$ Detectors," Proceedings of the 8th International Conference on Nuclear Photography and Solid State Detectors, Bucharest, 1972, Vol. I, pp. 384-393.

5. J. Barbier, "Contrast Improvement of Images Obtained in Cellulose Nitrate Film by Track Etch Methods," Trans. Amer. Nucl. Soc. $13,530(1970)$.

6. A. L. Frank and E. V. Benton, "Passive Neutron Detector with Energy Resolution Between $3 \mathrm{MeV}$ and $20 \mathrm{MeV}$, Final Report San Francisco University, Dept. of Physics, March 1974. 


\title{
STUDIES OF NEUTRON DOSIMETRY AT THE
}

LAWRENCE LIVERMORE LABORATORY*

\author{
D. E. Hankins \\ University of California \\ Lawrence Livermore Laboratory \\ Livermore, California 94550
}

\section{A Comparison Study of Remmeters}

A study of the directional response and the energy dependence of four neutron remmeters was made at the Los Alamos Scientific Laboratory. Part of this information is included in a note in the Health Physics Journal by D. E. Hankins and J. R. Cortez entitled, "Energy Dependence of Four Neutron Remmeter Instruments," Vol. 28, No. 3, pg. 305. Some points of the study not included in this journal paper were discussed, including directional response and thermal neutron responses.

\section{Evaluation of Neutron Exposures from LLL Personne 1 TLD Badges}

The dose delivered by thermal neutrons varies considerably when compared to the fast neutron dose; consequently, thermal neutrons are rarely used to determine the fast or total neutron dose. At the Lawrence Livermore Laboratory the personne1 TLD badge was not designed to measure the fast neutron dose. It contains three TLD's, a normal lithium fluoride (TLD 100), a lithium fluoride enriched in Li-7 (TLD 700) and a calciúm fluoride (TLD 200) chip. The TLD 100 responds with a high sensitivity to thermal neutrons, and is essentially insensitive to fast neutrons. The TLD 700 has no significant response to either fast or thermal neutrons.

To evaluate the neutron dose our personnel were receiving, based on the themal neutron readings of the badges, we made a study of the relationship between the reading of the TLD 100 and the TLD 700 chips when exposed to neutrons under field conditions. One complicating factor was

\footnotetext{
* Work performed under the auspices of the U.S. Energy Research and Development Administration.
} 
that the TLD 100 is located in the open window portion of the badge and was intended to measure beta and low-energy x-rays. Fortunately, we found that in most areas where a neutron dose was being received, there were no significant beta or low-energy $x$-ray exposures occurring.

To evaluate the fast neutron dose, it was necessary to know what part of the total neutron dose was being delivered by thermal neutrons.

Measurements were made with the PNR-4 neutron instrument to determine the total neutron dose rate. The $\mathrm{BF}_{3}$ probe was removed from the sphere and measurements were made with the bare probe to determine the thermal neutron dose rate. Extensive surveys were made in areas where neutron doses could be received. TLD badges were then planted on gallon jugs at many of these survey points and left for several hours. When the badges were read, the TLD 700 reading was subtracted from the TLD 100 reading and the remainder was divided by the dose to obtain the calibration factor. Specially loaded badges were prepared and placed on some of the jugs. These contained one TLD 100 and two TLD 700 chips with the TLD 100 being behind the beta shield of the badges. This was done to assure that there were no beta or lowenergy $x$-rays exposing the TLD 100 located in the open window portion of the personnel TLD badge.

Figure 1 is the curve that was drawn showing the calibration factor as a function of the percent of the neutron dose rate delivered by thermal neutrons. The calibration factors vary greatly, but it has been found that at any specific building or area the thermal neutron component of the neutron dose remains fairly constant and an evaluation of the badges to obtain the total neutron dose can be made within about \pm 50 percent. If the dose was received in several areas where the thermal component varied greatly, this procedure could not be used. It also cannot be used if beta or lowenergy $x$-ray exposures are present. To resolve the latter problem, the personnel TLD badges will be changed in the near future to contain one Li 100 and two Li 700 TLD's with the Li 100 TLD being behind the beta shield. We are also considering the addition of an albedo neutron dosimeter to measure the fast neutron dose directly. 


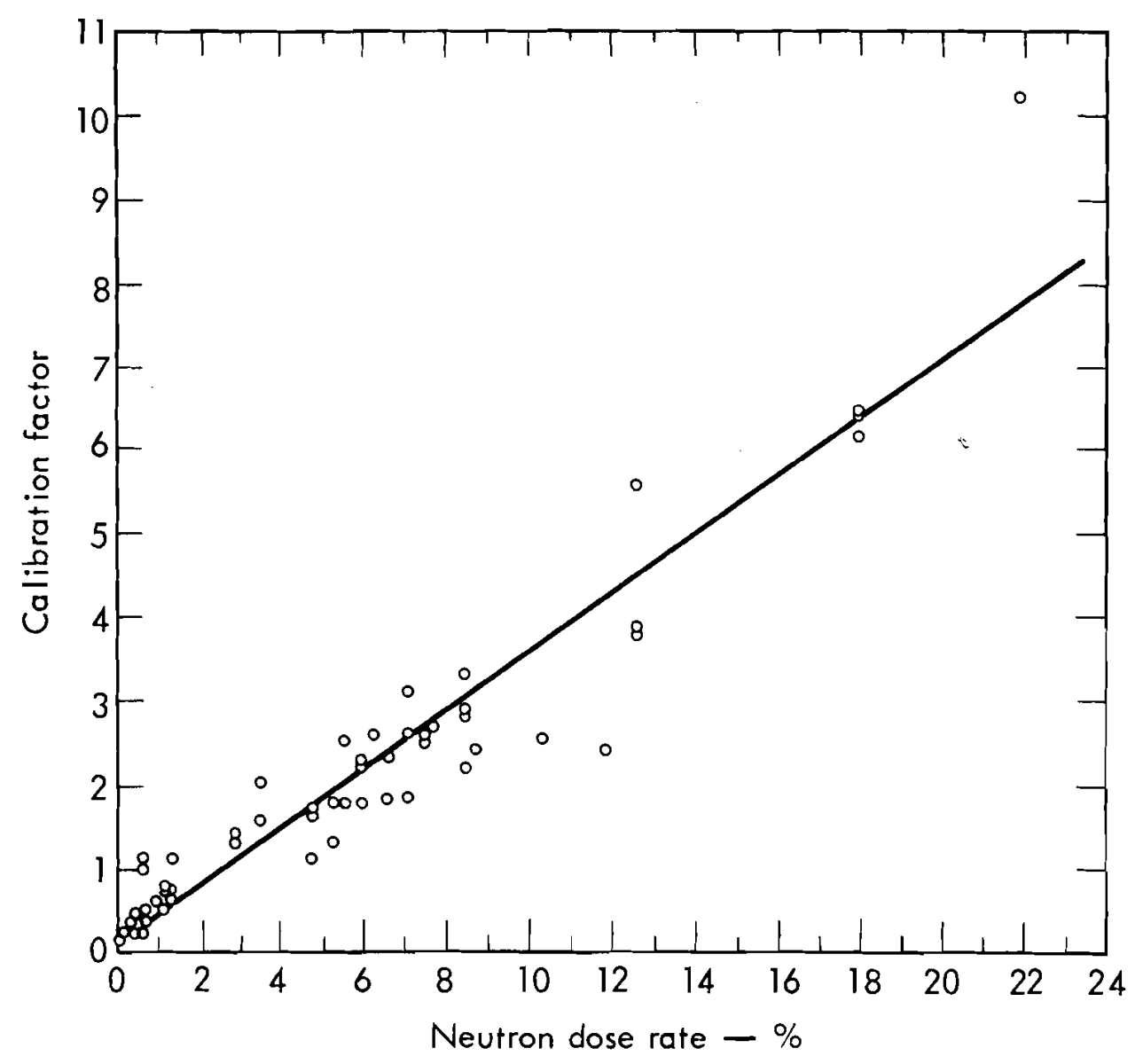

FIGURE 1. Curve Used to Obtain the Calibration Factor for Personnel TLD Badges

\section{Calibration Factors for Albedo-Neutron Dosimeters}

Albedo-neutron dosimeters are very energy dependent, and to use them accurately one must have information on the neutron energy spectrum and this spectrum must be fairly constant in the exposure area. A study of how well this condition is met at several facilities is shown in this paper.

The advantage of albedo-neutron dosimeters is that they do not have the energy threshold of around $1 \mathrm{MeV}$ that exists with NTA film and fission fragment damage dosimeters using $\mathrm{Np}$ or Th radiators. This means that lowenergy neutrons from reactors, accelerators, or some neutron sources are 
detected by albedo-neutron dosimeters, and no significant exposure from neutrons with energies $<10 \mathrm{MeV}$ would go undetected. The main disadvantage of the albedo-neutron dosimeters is their energy dependence.

The survey results shown in the following figures were made using a 3-inch, $10 \mathrm{Mil}$ cadmium covered sphere and the 9-inch cadmium loaded sphere, PNR-4 neutron remmeter instrument manufactured by Eberline Instrument Corp. The $\mathrm{BF}_{3}$ probe of the PNR-4 instrument was used in both spheres. The count obtained with the 9 -inch sphere is divided by the count obtained with the 3 -inch sphere. This ratio is found on a graph similar to Figure 6 in another report. (1) The calibration factor is obtained from the graph and plotted as a function of dose rate obtained from the 9-inch sphere count rate.

Figure 2 shows the results obtained at four reactors. (a) Results from the ATR located at the National Reactor Testing Station in Idaho. Few survey points could be found at this reactor because the dose rates were very low. (b) Results from the OWR at the LoS Alamos Scientific Laboratory, (LASL); (c) From the TREAT in Idaho; and (d) from the LPTR at Lawrence Livermore Laboratory (LLL). The results from a fifth reactor, the ZPPR also located in Idaho are shown in Figure $3(a)$.

With the exception of the ZPPR, albedo-neutron dosimeters could be expected to measure the neutron dose at these reactors within about \pm 40 percent, but the calibration factors between ractors vary from a high of 2.3 at the LPTR to a low of 1.4 at the OWR. The ZPPR is a critical assembly with the core mounted to permit it to be separated. The points to the right were obtained between the halves of the assembly. Those to the left were obtained in the reactor room and between the assembly halves with removable personnel shielding in place. When the shields are not in place, the energy of the neutrons is higher, giving lower calibration factors. The point with the $(X)$ is the data obtained with the shields separated about 7 -inch and represents the condition of the most common and significant exposure to personnel. Selection of a calibration factor of 0.63 was made to avoid underestimating the neutron dose by $>30$ percent and still be within a factor of two for the exposures at lower dose rates. 


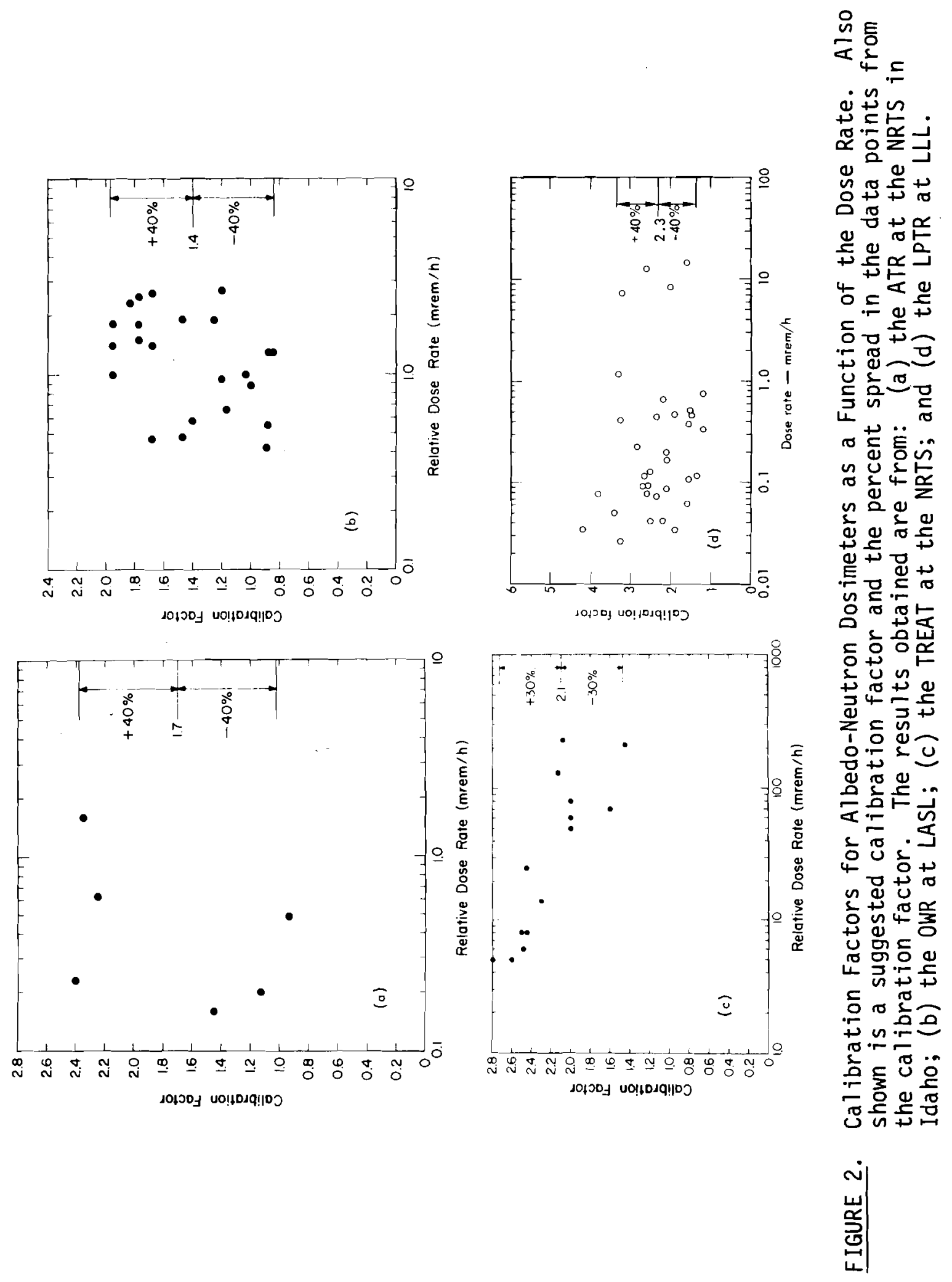



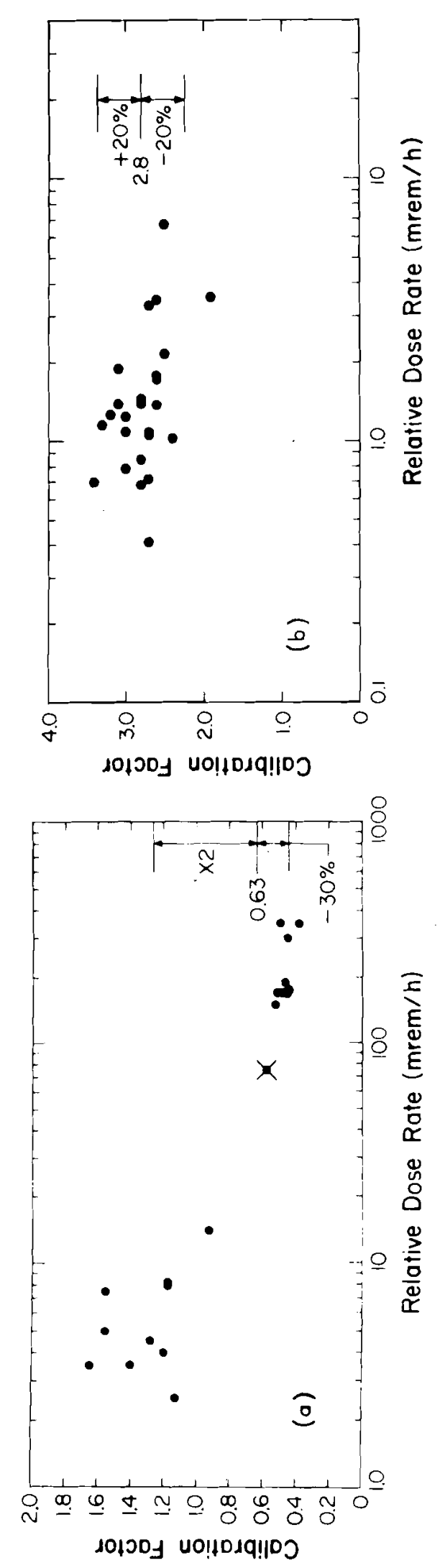
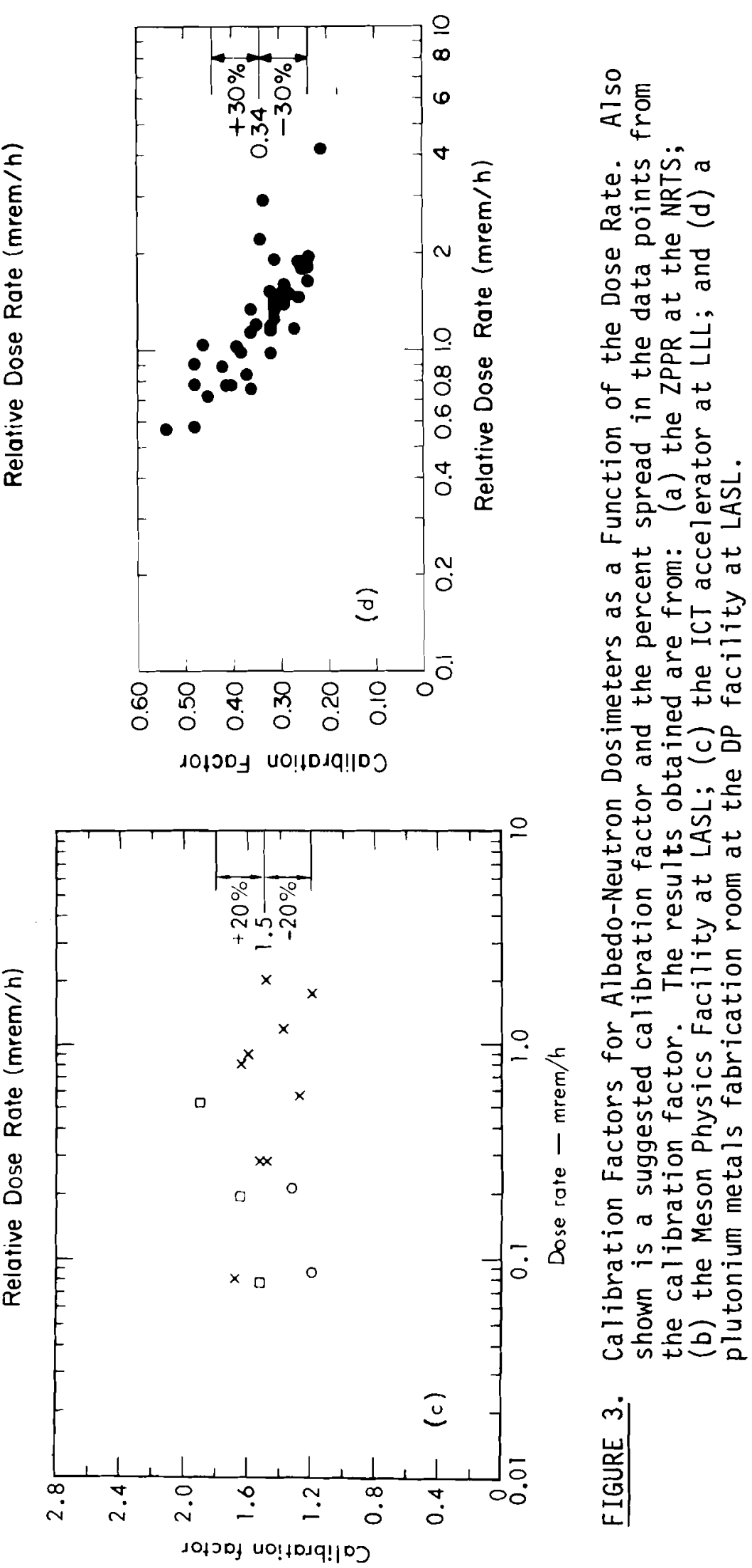
Figure 3(b) shows the results obtained at one of the target areas of the Meson Facility at LASL. These results indicate that the dose could be obtained within \pm 20 percent. Later, a new target area was opened, and it was found that the higher energy neutrons leaking from the shielding in this area required a much lower calibration factor for the albedo-neutron dosimeters. This requires that for proper badge evaluation, the locations where the individual received his dose be known.

Another accelerator study is shown in Figure $3(c)$. These results were taken at various distances from the shielding and in buildings near the ICT at LLL. In spite of the great variations in distance from the accelerator, it was found that a spread of only \pm 20 percent would apply at a calibration factor of 1.5 .

Results obtained at plutonium facilities are shown in Figure $3(d)$ and in Figure 4. The results from gloved box lines are shown in Figure 3 , Figure $4(a)$ and $4(b)$ and the points plotted with $(X)$ in Figure $4(d)$. There is an apparent trend for the calibration factor to be lower as the dose rate increases. This is not an indication of a dose rate dependence of the dosimeters, but is caused by the higher energy neutron spectrum which exists close to a piece of plutonium where the dose rates are higher compared to the more moderated or scattered spectrum that exists at larger distances. This is graphically illustrated in Figure 4 (d) for results obtained inside a large plutonium storage vault. The calibration factor drops rapidly and the dose rate increases as one measures closer to the plutonium. The results obtained in a small vault in Building 332 at LLL [the points with the $(\square)$ in Figure $4(d)$ ] do not show this effect because the dose rates throughout the vault are fairly constant. The results shown in Figure 5(a) were from a source storage facility. There is only a small trend to lower calibration factors at the higher dose rates, probably because all the neutron sources were shielded. The points plotted with the (0) in Figure $4(c)$ were obtained outside the source storage vault of Building 332. Here the spectrum of neutrons is fairly moderated, and a calibration factor of 1.1 can be applied with an expected dose measurement within \pm 25 percent. 


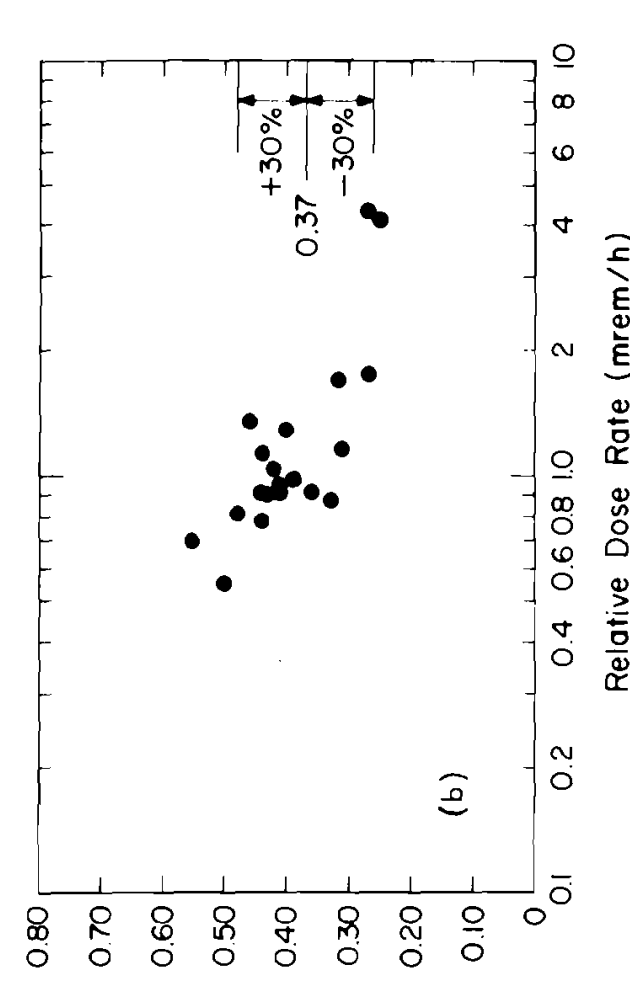

10100 y $401,1019 ! 105$
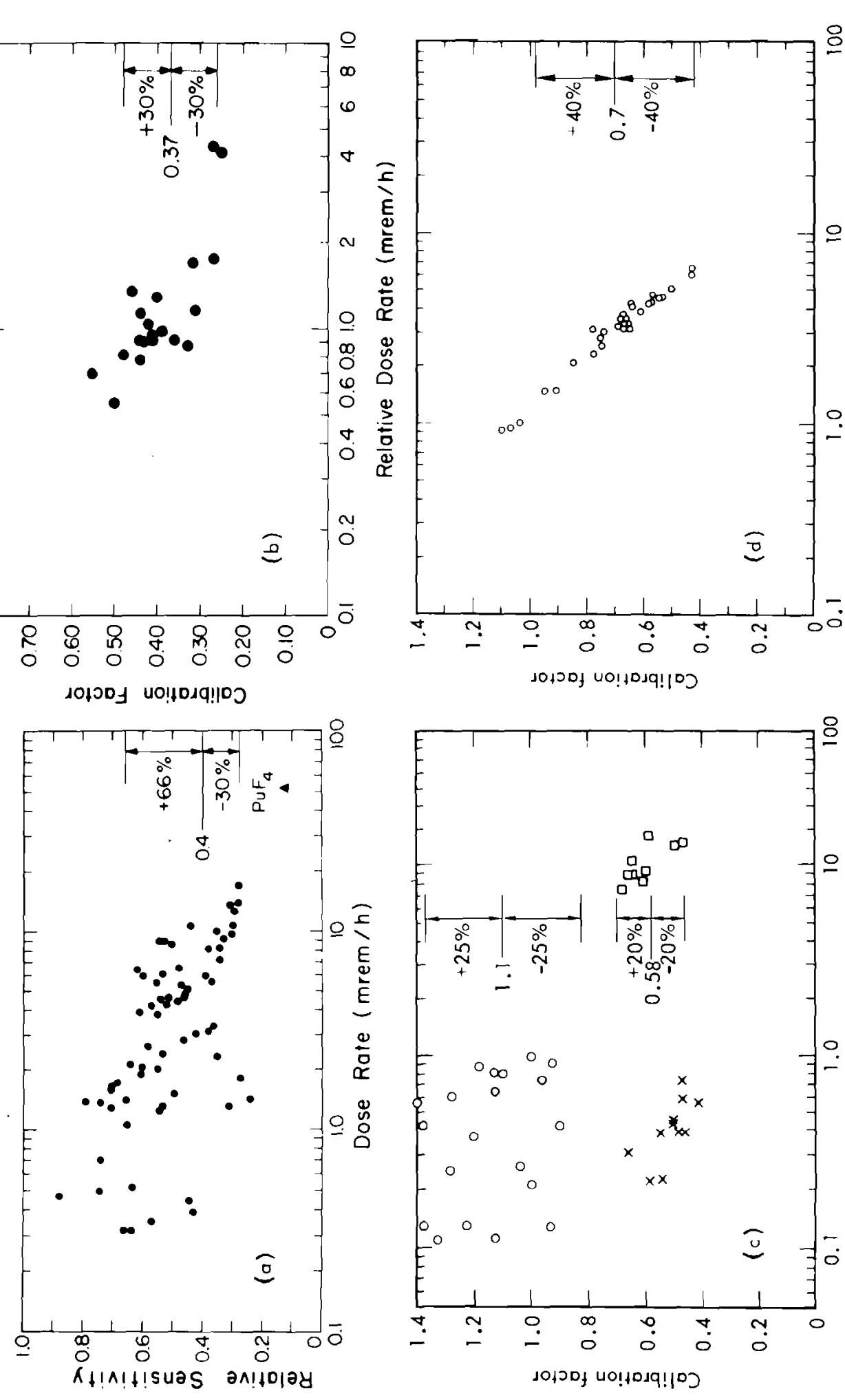

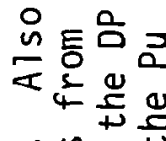

ind

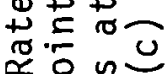

$\approx$ 응

凹

นิำㅇำ

ह 0 व

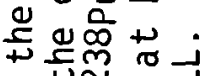

4 J

○.

ᄃำ

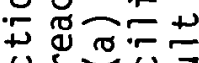

U⿺辶万人

山.

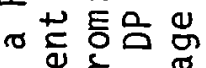

$\backsim$ थ 4

ช选过市

ฯ 2

过耑

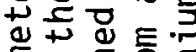

E.

in 듣요웅

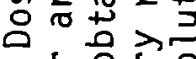

ᄃ ᄂ

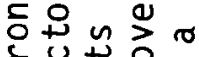

市㟧

वृष जै응

둥ㄹ..

음 후

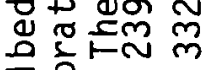

<盗.

ธ。

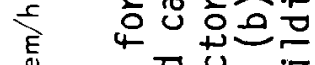

थ 80.

气些苛品

엉

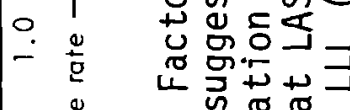

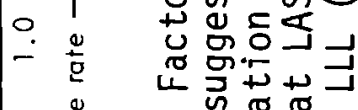

$\begin{array}{lllll} & 0 & 0 & & \\ 0 & 0 & 0 & & x \\ 0 & & 0 & & x\end{array}$

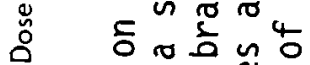

平

ס

气

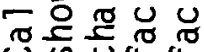

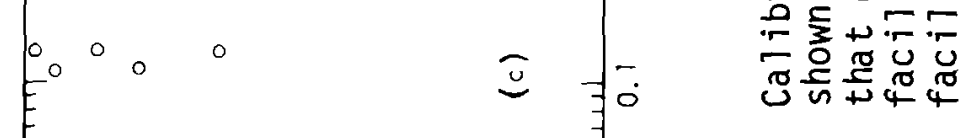

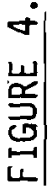



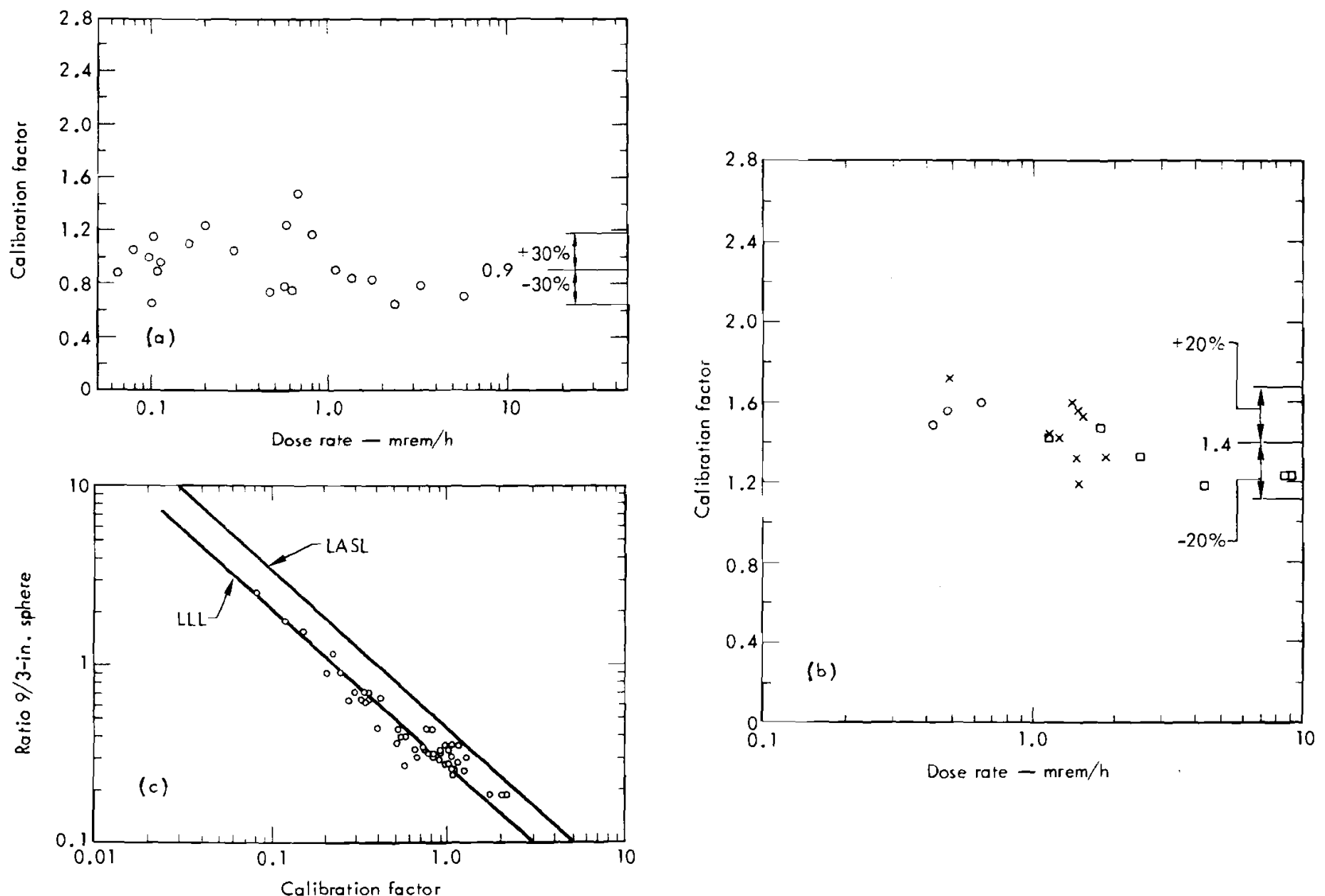

FIGURE 5. (a) Calibration Factors for Albedo-Neutron Dosimeters as a Function of Dose Rate obtained from a Source Storage Area. (b) From the radiochemistry building at LLL. (c) Curve shows the difference in the calibration factos at LLL and LASL caused by variations in the TLD's. The points are experimental results obtained at LLL. 
Figure $5(a)$ shows the results obtained near and in rooms adjoining a shielded gloved box containing ${ }^{244} \mathrm{Cm}$ at the LLL Radiochemistry facility. The box is shielded by $\sim 1$ foot of water on its front and sides, but is unshielded on the top, bottom, and back. A spread of only about \pm 30 percent was found for the calibration factors around this box.

The ${ }^{6} \mathrm{Li}$ TLD's used in the recent work at LLL are 25 mil thick compared to the $35 \mathrm{mil}$ thickness used at LASL. The thinner TLD's are less sensitive, and results obtained at LLL show a definite bias to the right of the curve obtained using LASL TLD's [Figure $5(\mathrm{c})$ ]. Before using the LASL curve, one should perform calibration checks to determine the sensitivity of the TLD's.

Table 1 gives a summary of the calibration factors selected for each of the facilities as shown in the preceding figures. They vary from a low of 0.34 to a high of 2.8 which is a factor of about eight for the facilities surveyed. Even lower calibration factors would exist for other facilities where higher energy neutrons are present (no calibration factors higher than 2.8 have been found).

Although the evaluation of an individual's dose occurring in a single facility can be reasonably accurate (see last column of Table 1), one must know in which facility the person was exposed. Also, the person's exposure must occur in a single facility, or in a facility where a similar calibration factor would apply. If these conditions are not met, large errors in the evaluation of a person's dose could occur. 


\section{TABLE 1. Summary of the Calibration Factors}

for the Various Facilities

Facility

Meson facility

TREAT reactor

Fabrication wing of a ${ }^{239} \mathrm{Pu}$ facility

Recovery wing of a ${ }^{239} \mathrm{Pu}$

facility
${ }^{238} \mathrm{Pu}$ facility

ATR

OWR

ZPPR

LPTR

Building 231 vault

Building 332 in vault

Building 332 outside vault

Building 332 glove boxes

Building 255 shielded box

ICT

Building 233 source storage area
Calibration Factor $\begin{aligned} & \text { Observed Spread In } \\ & \text { Calibration Factors }\end{aligned}$

2.8

\pm 20 Percent

2.1

\pm 30 Percent

0.34

\pm 30 Percent

0.37

0.4

1.7

1.4

0.63

2.3

0.7

0.58

1.1

0.58

1.4

1.5

0.9 \pm 30 Percent

+66 Percent, -30 Percent

\pm 40 Percent

\pm 40 Percent

$+\times 2,-30$ Percent

\pm 40 Percent

\pm 40 Percent

\pm 20 Percent

\pm 25 Percent

\pm 20 Percent

\pm 20 Percent

\pm 20 Percent

\pm 30 Percent

\section{Reference}

1. "A Sma11 Inexpensive Albedo-Neutron Dosimeter," LASL, LA-5201. 
RESPONSE OF SAVANNAH RIVER THERMOLUMINESCENT

NEUTRON DOSIMETER TO MONOENERGETIC NEUTRONS*

\author{
J. E. Hoy \\ Savannah River Laboratory \\ and \\ R. M. Hall \\ Savannah River Plant \\ E. I. du Pont de Nemours \& Co. \\ Aiken, South Carolina 29801
}

\title{
Introduction
}

The Thermoluminescent Neutron Dosimeter (TLND) is an albedo-type detector designed to respond in a manner approximately proportional to the dose equivalent. The dosimeter was intended to be used in a normal working environment where a complete spectrum of neutron energies occur and where monoenergetic neutrons are practically nonexistant. However, knowledge of the response of dosimeters to monoenergetic neutrons can assist in understanding the observed response to continuous spectra. Experimental results for monoenergetic neutron exposures, at thermal and at energies greater than $125 \mathrm{keV}$, have been published. (1) Theoretical responses of the TLND for individual energy points between thermal and $400 \mathrm{MeV}$ have also been calculated by Alsmiller. ${ }^{(2)}$ Both empirical and theoretical results agree for neutron energies above $1 \mathrm{MeV}$ but differ by a factor of 10 at $125 \mathrm{keV}$. Calibrated monoenergetic neutron beams with energies of thermal, $2 \mathrm{keV}$, and $25 \mathrm{keV}$ at the NBS reactor provided the opportunity to measure the TLND response at these energy points. The empirical and the calculated TLND responses for energies of thermal, $2 \mathrm{keV}$, and $25 \mathrm{keV}$ are compared in this paper.

* The information contained in this article was developed during the course of work under Contract No. AT(07-2)-1 with the U.S. Energy Research and Development Administration. 


\section{Experimental Results}

TLND's were exposed to a calibrated ${ }^{252} \mathrm{Cf}$ neutron fission spectrum at NBS during these tests, and the dose equivalent data obtained were compared with similar data documented previously. The purpose of this test was to ensure that no changes in the dosimeters had occurred since the last monoenergetic series of tests made in 1971. No significant differences in response or interpretation of results were noted, and the current calibration factor was determined to be valid.

In each irradiation, the TLND was belt-mounted against the midsection (only the $25 \mathrm{~cm}$-high waist section was used) of a Rando phantom. All irradiations were made with the neutron beam normally incident to the front of the phantom. Because of the small diameter of the exposing beam, the phantom was mechanically moved in a systematic pattern to expose an area of $476 \mathrm{~cm}^{2}(27.5 \mathrm{~cm} \times 17.3 \mathrm{~cm})$. Two TLND measurements were made at each neutron energy.

Table I compares the results obtained from these tests with dose equivalents delivered by the NBS neutron beams.

\section{TABLE I. Response of TLND Exposed to NBS Neutron Beams}

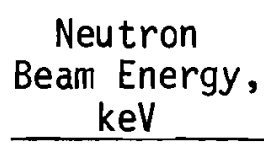

25

2

Therma 1

Control

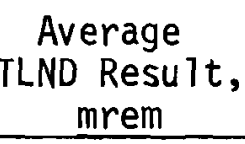

40

1700

120

$<10$

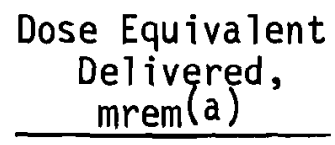

65

46

400

0

(a) Based on NCRP Report No. 38 (January 4, 1971) at $0.5 \mathrm{~cm}$ tissue depth. 
The measured response at these energies and similar data for higher energies measured in 1971 are compared with the calculated response of the TLND in Figure 1. All data are normalized to $1.6 \times 10^{6}$ reactions $/ \mathrm{rem}$. At $25 \mathrm{keV}$, the measured response was low (0.6); theoretical calculations predicted the response would be high by a factor of 50. At $2 \mathrm{keV}$, the TLND response overestimated the dose equivalent by a factor of $\sim 40$; the calculated response predicted an overestimate by a factor of 100 .

The relative response of the TLND exposed to the thermal beam at NBS was lower than that observed for the SRP thermal beam. This difference was attributed to the quality of the NBS thermal beam (fewer neutrons with energies above cadmiun cutoff). Consequently, the dose equivalent was underestimated by a factor of 23 ; however, negative results (i.e., the response of the front-most detector subtracted from the response of the detector near the body) were not obtained as implied by calculations.

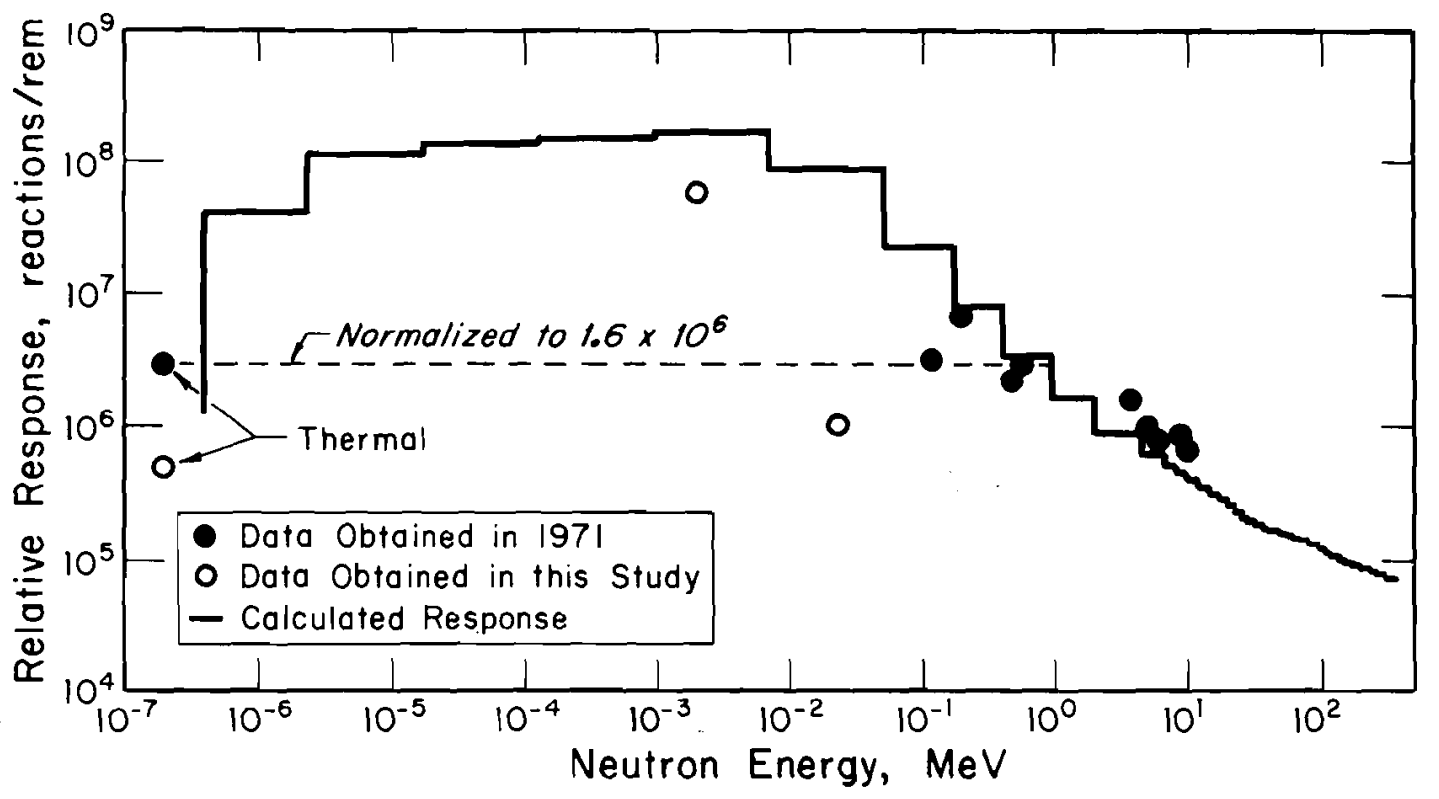

FIGURE 1. Empirical Response of the TLND Compared to the Calculated Response 
In conclusion, the TLND was found to vary in energy response but not to the degree predicted by calculations. No neutron dosimeter responds correctly to a wide spectrum of neutrons. The TLND does as we11 as any dosimeter, and its continued use is warranted. This is particularly true at facilities where workers are exposed to continuous neutron spectra.

\section{References}

1. J. E. Hoy, Personnel Albedo-Neutron Dosimeter with Thermolumenscent $6 \mathrm{LiF}$ and $7_{\mathrm{LiF}}$. USAEC Report DP-1277, E. I. du Pont de Nemours \& Co., Savannah River Laboratory, Aiken, SC, 29801.

2. R. G. Alsmiller, Jr., and J. Barish, The Calculated Response of AlbedoNeutron Dosimeters to Neutrons with Energies $\leq 400 \mathrm{MeV}$. USAEC Report ORNL-TM-3984, Oak Ridge National Laboratory, Oak Ridge, TN, 1972. 
NTA PROTON RECOIL TRACK FADING IN PERSONNEL NEUTRON DOSIMETRY

\author{
L. F. Phillips \\ Health Physics and Safety Division \\ Brookhaven National Laboratory \\ Upton, NY 11973 \\ May, 1975
}

Two Kodak NTA proton track fading studies were performed using two different types of sealing packets and storage at 100 percent relative humidity (R.H.).

Unexposed NTA film were desicated then heat sealed, with a desicant, inside moisture "resistant" packets and then exposed to neutrons from a $5 \mathrm{Ci}$ PuBe neutron source. The neutron exposures and film processing schedules allowed a variable storage time in the 100 percent R.H. environment. Routine film processing and scanning techniques were performed. The table below summarizes the treatments employed in each study.

\begin{tabular}{|c|c|c|c|c|c|}
\hline $\begin{array}{c}\text { Study } \\
\text { No. }\end{array}$ & $\begin{array}{l}\text { Preexposure } \\
\text { Desication } \\
\text { (Days) } \\
\end{array}$ & $\begin{array}{r}\text { Moisture } \\
\text { Resistant } \\
\text { Packet } \\
\end{array}$ & $\begin{array}{c}\text { Desicant } \\
\text { Stored in Packet } \\
\text { Molecular Sieve } \\
\text { Type } 3 \mathrm{~A} \\
\end{array}$ & $\begin{array}{l}\text { No. of } \\
\text { Film Per } \\
\text { Exposure } \\
\text { Unit } \\
\end{array}$ & $\begin{array}{l}\text { Post Exposure } \\
\text { Storage Time } \\
\text { at 100\% R.H. }\end{array}$ \\
\hline I & 3 & $\begin{array}{l}\text { Two Layers } \\
\text { Polyethyl- } \\
\text { ene } 4 \mathrm{mg} / \mathrm{cm}^{2} \\
\text { each }\end{array}$ & $0.8 \mathrm{gr}$ & 2 & $0,1,2,3,4$ weeks \\
\hline I I & 27 & $\begin{array}{l}\text { One Layer } \\
\text { Plastic- } \\
\text { coated Al }\end{array}$ & $\sim 1 \mathrm{gr}$ & 4 & $0,1,2,3$ months \\
\hline
\end{tabular}

Results are summarized in the graph.

Under the most unfavorable conditions of total neutron exposure at $T_{0}$ and postexposure storage at 100 percent R.H., Run II with the plasticcoated Al packet appears more effective than Run I, and has acceptable fading in about 1 month. 


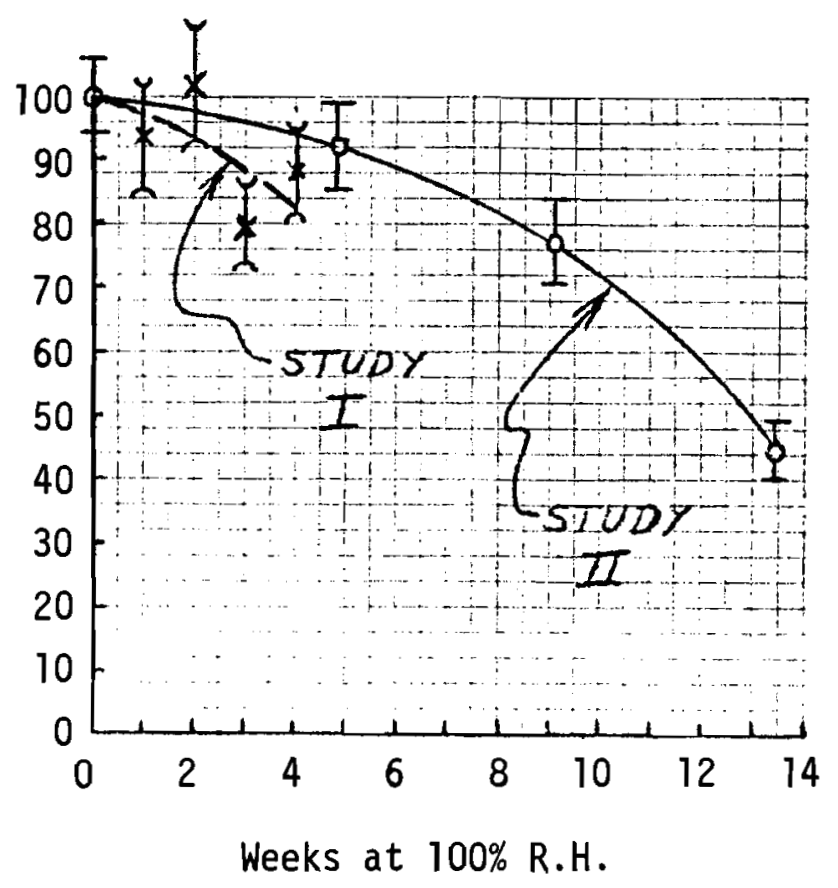

Tracks Remaining Per 25 Fields, Normalized to $100 \pm \sigma T / 25 \mathrm{~F}$ At $\mathrm{T}_{0}$ 


\section{PERSONNEL NEUTRON DOSIMETRY AT SLAC*}

\section{D. Busick, T. M. Jenkins, and W. P. Swanson Stanford Linear Accelerator Center Stanford, California 94305}

At SLAC, more than 90 percent of the recorded personnel doses are caused by photon radiation, and consequently neutron exposures are a minor problem. SLAC has a program of personnel dosimetry using ${ }^{6} \mathrm{LiF} /{ }^{7} \mathrm{LiF}$ TLD dosimeters. These are Teflon disks that are incorporated in a wallet identification card. No moderation is provided, other than that afforded by the body of the wearer. Approximately 200 SLAC employees are classified as Radiation Workers, and their dosimeters are read quarterly. Most of these individuals are issued one disc each of ${ }^{6} \mathrm{LiF}$ and ${ }^{7} \mathrm{LiF}$. A few individuals are given dosimeters with several of each disc, to provide additional precision in subsequent dose assessment. The remaining SLAC employees (about 1000) are issued an "accident dosimeter" that is read annually. Visitors, both long and short-term, are also provided with an accident dosimeter (400-500 each year).

Doses imparted to individuals tend to be significantly smaller when the accelerator is operating. The largest doses are actually imparted during down times when repair and maintenance work is done near activated components. All components of the radiation field are small in the occupied areas during periods of operation, even in the Research Area, and this is the only time when neutron exposure rates would be present.

The significant sources of neutron radiation are located in the Research Area: End Stations A, B, C, as well as SPEAR. Neutrons are produced by the giant-resonance nuclear photoeffect $(1)$ and by higher energy photonuclear processes (predominantly from pion photoproduction).

* Work performed under auspices of the U.S. Energy Research and and Development Administration. 
For shield thicknesses greater than about 2 feet of concrete, the higher energy neutrons will have reached an equilibrium spectrum. (3) In the Research Area, we make the assumption that this equilibrium spectrum is uniformly constant everywhere. Further, we assume that the ratio of thermal neutron flux to this fast neutron flux is constant wherever recordable neutron doses can be received.

There are no other neutron sources, apart from small PuBe sources for calibration purposes. Because the spectra of the sources is assumed to be uniform, and the neutron doses are historically small, we have been able to operate using a simplified dosimetry procedure. If we had multiple sources of neutrons of various types, or a history of large doses to individuals, we would be more interested in developing and using a "universal" neutron dosimeter.

The present system of neutron personnel dosimetry at SLAC is based on the following history. First, a calibration was performed by $G$. Svensson, in $1971,{ }^{(4)}$ for thermal neutrons for the particular type of TLD material used at SLAC. Next, for fast neutron calibration, he exposed the ${ }^{6} \mathrm{LiF}$ material, backed by varying thicknesses of paraffin, to a PuBe source. He found that the response of the TLD increased rapidly as the paraffin backing thickness was increased, until thicknesses of about 1.5-inch were achieved. Thereafter, the sensitivity was quite flat, out to at least 6-inch. These results were consistent with the sensitivity obtained for the same material at the center of a 4-inch diameter paraffin sphere.

Next, a series of experiments was performed in which a phantom consisting of a water-filled polyethylene cylinder of diameter $25 \mathrm{~cm}$ and height $40 \mathrm{~cm}$ was used. The TLD material was attached to this cylinder, which was rotated at a constant rate. This arrangement was exposed to PuBe and PuF sources in a tunnel where the ratio of fast to thermal fluxes could be varied over a range that encompassed the ratios measured at various locations in the Research Area. Within this range, the dosimeters proved to be sensitive only to the thermal flux already present: i.e., there was no change in response due to the presence of the water phantom, for fast/thermal flux ratios less than about 10 . 
The ratio of fast to thermal neutrons was determined at eight locations around the Research Area at SLAC, extending over periods of more than 1 year. These determinations were made by using the ratio of simultaneously exposed moderated and unmoderated TLD dosimeters. These flux ratios ranged between 1 and 11 , but most of the 32 individual ratios were clustered between 2 and 4 . The average flux ratio for all determinations turned out to be 3.4. When converted to dose equivalent ratios, using the conservative assumption that the neutron quality factor is 10 , the ratio of 110 rem (fast neutrons)/1 rem (thermal) is obtained.

In the SLAC program, we actually assume a ratio of six (rather than 3.4) for the fast/thermal fluences. Thus we are conservative by almost a factor of two in this parameter. In converting to dose equivalent in rem, a factor of 33 is employed. This is the ratio of fluence to doseequivalent conversion factors at the two energies assumed: Thermal and the average energy of our fast neutrons, which is taken to be about $1.0 \mathrm{MeV}$. Thus to obtain a final dose assessment for an individual, we multiply the thermal dose assessment in rem by a factor of 200 .

Actual information on the neutron spectrum at SLAC outside the shielding is very sparse. In a series of experiments using a proton recoil counter-moderated $\mathrm{BF}_{3}$ counter combination, it was found that the average energy lay in the range 0.5 to $4.0 \mathrm{MeV}$. This overlaps the range of neutron energies found to be typical in experiments done at the various accelerator laboratories, ${ }^{(5)}$ in which average energies are found in the range 0.2 to $8.0 \mathrm{MeV}$.

Although the neutron personnel dosimetry problem is mainly of academic interest to us, more accurate information on the neutron energy spectrum outside the shielding would be useful. This would be of value mainly in assessing the population dose equivalent, rather than for personnel dos imetry. 


\section{References}

1. See, for example, Evans Hayward, "Photonuclear Reactions," NBS Monograph 118, U.S. National Bureau of Standards, Washington, DC, 1970.

2. See, for example, H. Wade Patterson, and Ralph H. Thomas, "Accelerator Health Physics," Ch. 3, pp. 114-117, Academic Press, New York and London, 1973.

3. W. S. Gilbert, D. Keefe, J. B. McCaslin, H. W. Patterson, A. R. Smith, L. D. Stephens, K. B. Shaw, G. R. Stevenson, and R. H. Thomas, "1966 CERN-LRL-RHEL Shielding Experiment at the Cern Proton Synchrotron," UCRL-17941, UC-28, TID-4500 (53rd Ed.), 1968.

4. Goran Svensson, private communication, Stanford Linear Accelerator Center, Stanford, CA, 1971.

5. See, for example, G. Bathow, U. Clausen, E. Freytag, and K. Tesch, "Skyshine Measurements and Their Comparison with Estimates from Diffusion Theory," Deutsches Elektronen-Synchrotron, Hamburg, Report No. DESY 66/3 (1966). 


\title{
ACTIVITIES IN NEUTRON DOSIMETRY
}

\author{
R. Taubert \\ Physikalisch-Technische Bundesanstalt \\ Abteilung 6 / Abteilung 7 \\ D 33 Braunschweig, Bundesallee 100 \\ Germany
}

A. An Accelerator Installation for Neutron Dosimetry (Abteilung 6)

An accelerator facility is being brought into operation at the PTB (Physikalisch-Technische Bundesanstalt) this year. It comprises two accelerators: an HVEC (High Voltage Engineering) Van de Graaff and a TCC (The Cyclotron Corporation) Cyclotron ( $C V 28$ ). The energies and specified currents of the accelerators are:

Van de Graaff:

$$
\begin{array}{ll}
\text { Voltage: } & 0.3 \text { to } 3.75 \mathrm{MV} \\
\text { Ions: } & \mathrm{H}^{+}, \mathrm{D}^{+},{ }^{3} \mathrm{He}^{+},{ }^{3} \mathrm{He}^{++},{ }^{4} \mathrm{He}^{+},{ }^{4} \mathrm{He}^{++} \\
\mathrm{H}^{+} \text {-Beam (max): } & 500 \mathrm{HA} \\
\text { Pulsed Beam: } & 5 \mathrm{HA} \text { at } 1 \mathrm{MHz} \text { repetition rate and } \\
& <2 \cdot 10^{-9} \mathrm{sec} \text { duration } \\
& \text { Variable repetition rate: } 0.2 \text { to } 2 \mathrm{MHz} . \\
& \text { Preacceleration clystron bunching }
\end{array}
$$

\begin{tabular}{|c|c|c|}
\hline Particle & Energy (MeV) & Current $(\mu A)$ \\
\hline $\mathrm{H}^{+}$ & $2-24$ & $100-70$ \\
\hline $\mathrm{D}^{+}$ & $3-14$ & 100 \\
\hline${ }^{3} \mathrm{He}^{++}$ & $5-36$ & 10 \\
\hline${ }^{4} \mathrm{He}^{++}$ & $6-28$ & 10 \\
\hline
\end{tabular}

Cyclotron: 
Additional internal pulsing unit for repetition rates from 0.5 to $10 \mathrm{MHz}$ with pulse duration of $1 \cdot 10^{-9} \mathrm{sec}$.

We are able to produce monoenergetic neutrons of $10 \mathrm{keV}$ to $30 \mathrm{MeV}$ by means of 0.3 to $24 \mathrm{MeV}$ protons and 0.3 to $14 \mathrm{MeV}$ deuterons.

The experimental area is well shielded against the accelerators. The distances of the walls from the target and detector position are such as to keep backscattering small (see Figure 1). The target is $6.25 \mathrm{~m}$ above the concrete floor. The total height of the room is $14 \mathrm{~m}$.

The Van de Graaff $(5)$ is positioned at the 1. floor (the numbers correspond to those of Figure 1). The beam is brought via a $90^{\circ}$ bending magnet $(4)$ and a switching magnet ${ }^{(3)}$ to different target positions. At the target $(1)$ several detector mounts ${ }^{(2)}$ are installed which allow to rotate the detector around the target and to change the detector-target distance easily. The cyclotron $(6)$ is positioned in the basement. Its beam is guided through several magnets into the switching magnet. (3)

The two main projects that are started presently are:

1. Calibration of Neutron Dosimeters

The neutron fluence has to be measured for this purpose. The methods we chose are a proton recoil proportional counter with methane and hydrogene filling, a proton recoil telescope with a tristearate radiator and the associated particle detection from reactions with light nuclei. We intend to measure fluences with good accuracy. We take part in the present international comparison of neutron fluences organized by the BIPM. The calibration of Neutron Dosimeters for radiation protection will be started this year. A European intercomparison of neutron personnel dosimeters is planned at PTB by the Commission of the European Communities--Directorate-General Social Affairs (Health Protection) in 1976.

2. Elastic and Inelastic Neutron Cross Sections

A neutron time of flight installation consisting of eight scintillation detectors with collimators is in the stage of planning and construction. 


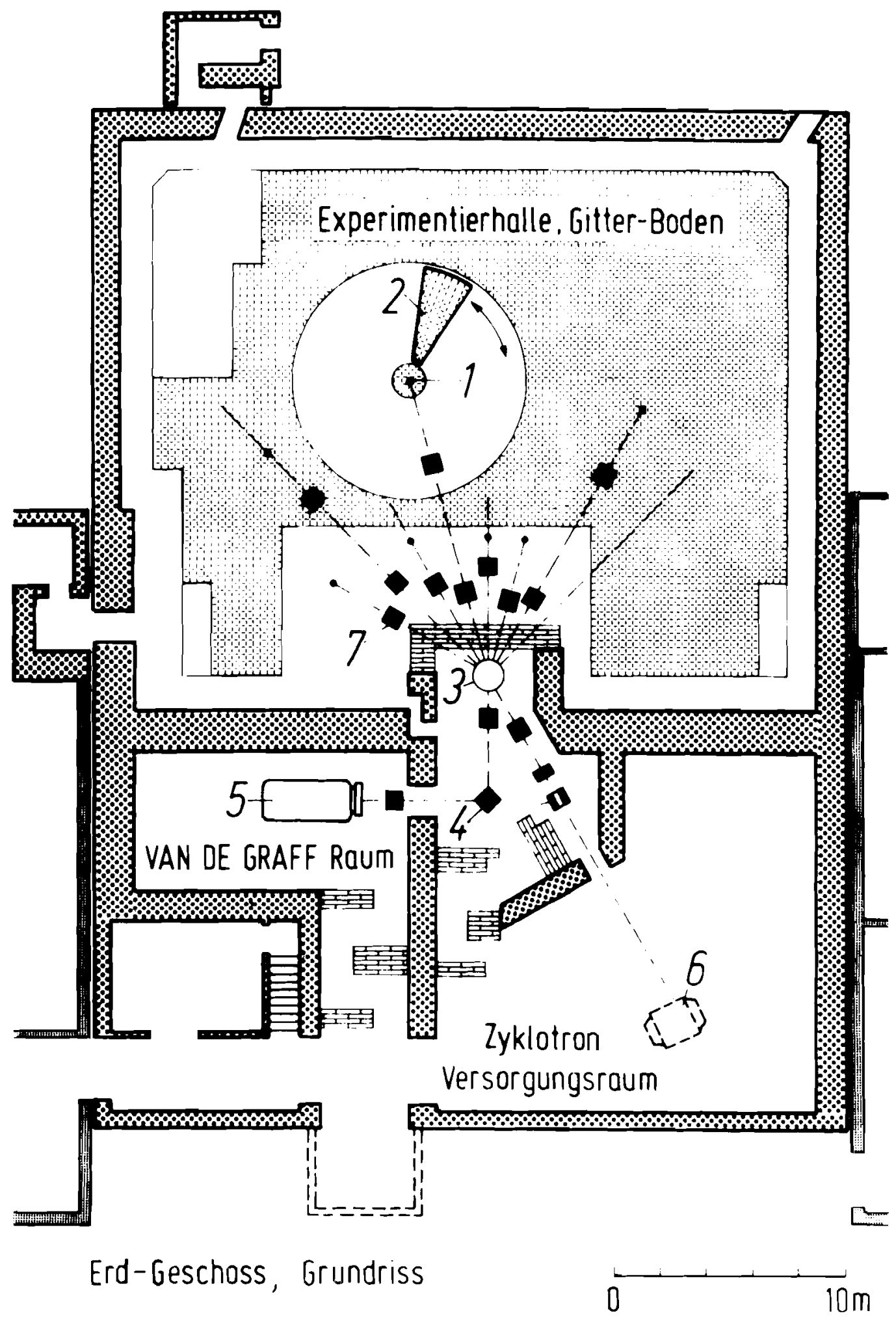

FIGURE 1. 
B. Other Activities (Abteilung 7)

1. At the PTB-reactor (FMRB) two neutron filters are under construction. Energies of $2 \mathrm{keV}$ and $25 \mathrm{keV}$ will be available.

2. Furthermore are available:

a. A well defined beam of thermal reactor neutrons for the calibrations of large dosimeters,

b. a thermal neutron flux standard,

c. a Californium-252 low scatter irradiation facility.

3. Development work on exoelectron dosimeters for individual neutron monitoring is underway.

4. The application of the Hurst proportional counter dosemeter is extended to neutrons of energies in the $10 \mathrm{keV}$ range. 


\title{
PERSONNEL NEUTRON DOSIMETRY
}

\author{
I. M. G. Thompson \\ Centra] Electricity Generating Board \\ Berkeley Nuclear Laboratories \\ Gloucestershire GL 139PB \\ UK
}

Theoretical studies of the albedo process have been compared to experimental measurements to obtain a best estimate. This estimate has been used to design an albedo personal dosimeter for measuring neutron dose for energies from thermal to $10 \mathrm{keV}$. The dosimeter's thermal neutron shield is made from a plastic moulding evenly loaded with boron carbide. Its shape and dimensions have been chosen to approximate the peak body rem dose for thermal and intermediate neutrons and to minimize errors arising from the observed variable dosimeter to wearer geometry (Harvey, J. R., et al., 1972 I.A.E.A. Symposium on Neutron Monitoring for Radiation Protection Purposes, Paper SM 167/43).

Doses measured with the dosimeter are converted to total neutron doses, from thermal to $10 \mathrm{MeV}$, by calculated ratios determined from measurements using a Basson detector, a rem counter and a thermal neutron detector. These ratios have been determined from many locations for several of the nuclear stations. The dosimeter has been in operational use within the C.E.G.B. for the past 4 years and the doses measured have been compared to those determined by the neutron track plate.

Investigations at B.N.L. and jointly with Euratom on methods of producing calibration sources of neutrons with energies below $24 \mathrm{keV}$ have been discussed. $\mathrm{A} \mathrm{Sb} / \mathrm{Be}$ source surrounded by water and enclosed in a boron sphere has been constructed (Harvey \& Bending, to be published, Phys. Med. \& Biology). This source has a mean energy of $1 / 2 \mathrm{keV}$ and has been used to measure the response of rem counters and the De Pangher long counter. 
FAST-NEUTRON PERSONNEL DOSIMETRY WITH TRACK RECORDERS*

\author{
T. J. YuTe \\ Argonne National Laboratory \\ Argonne, Illinois 60439
}

The use of track-recorder fast-neutron personnel dosimeters at the Zero-Power Critical facilities was described at the last workshop and is reported in detail in Reference 1. In brief, the dosimeter consists of two preetched mica track recorders with ${ }^{235} U$ foil sources mounted on a small card. One track recorder and source set is enclosed in aluminum, while the other set is enclosed in cadmium. The track density in the cadmium-covered recorder, $T_{c d}$, and the cadmium ratio, CR (the ratio of the track density in the aluminum-covered recorder to that in the cadmiumcovered one), are used to infer the dose from the equation:

$$
\text { Dose }=[a-b(C R)] T_{c d} \text {. }
$$

The constants $a$ and $b$ were empirically determined such that the inferred dose is equal to or greater than the actual dose for all neutron spectra encountered at the facilities.

Since the last workshop, approximately 300 dosimeters have been used. The reporting period is usually for 1 or 2 months. A skilled technician can read out the two recorders with an optical microscope in about 20 minutes.

To have a daily indication of the rate at which personnel are being exposed, a scale factor is determined each morning that approximately relates the neutron dose to the gamma-ray dose. The neutron dose is usually 5 to 10 times the gamma-ray dose.

* Work sponsored by the U.S. Energy Research and Development Administration under contract with the Argonne National Laboratory. 
At the present time we are investigating the use of spark counting and of a scanning electron microscope that is interfaced to a computer, for automatic readout.

\section{Reference}

1. R. J. Armani, R. Gold, G. K. Rusch, and T. J. Yule, Nucl. Instr. and Meth. 118, p. 383, 1974. 


\section{DISTRIBUTION}

No. of

Copies

OFFSITE

A. A. Churm (1)

ERDA Chicago Patent Group

U.S. Energy Research and

Development Administration

9800 South Cass Avenue

Argonne, IL 60439

E. J. Vallario (25)

Division of Operational Safety

U.S. Energy Research and Development Administration Washington, DC 20545

J. P. Cusimano (10) Health Physics Laboratory

U.S. Energy Research and Development Administration P.0. Box 2108 Idaho Falls, ID 83401

Sy Block (10)

U.S. Nuclear Regulatory Commission Washington, DC 20545

Robert J. Butenhoff (10)

U.S. Energy Research and Development Administration Washington, DC 20545

James E. McLaugh 1 in (10)

U.S. Energy Research and Development Administration washington, DC 20545

Ferene Hajnal (10) Radiation Physics Division U.S. Energy Research and Development Administration Health and Safety Lab. - NY 376 Huds on Avenue New York, NY 10014
T. J. Yule (10)

Argonne National Laboratory

Applied Physics Division

9700 Cass Avenue

Argonne, IL 60439

Jacob Sedlet (10)

Argonne National Laboratory

Applied Physics Division

9700 Cass Avenue

Argonne, IL 60439

Carl Distenfeld (10)

Brookhaven National Laboratory

Associated Universities, Inc.

Upton, NY 11973

L. F. Phillips (10)

Brookhaven National Laboratory

Health Physics and Safety

Division

Upton, NY 11973

Roger Falk (10)

The Dnw Chemical Company

Rocky Flats Division

P.0. Box 888

Golden, CO 80401

V. Ba lasubrahmanyam (10)

Department of National Health and Welfare

Ottawa, Ontario

Canada

I. M. G. Thompson (10)

Central Electricity Generating Board

Berkeley Nuclear Laboratories Gloucestershire GL 139 PB 


\section{DISTRIBUTION (contd)}

Jack Hoy (10)

E. I. du Pont de Nemours \& Co. Savannah River Plant

Aiken, SC 29801

Harry Howe (10)

Accelerator Laboratory

Accelerator Section

P.0. Box 500

Batavia, IL 60510

Dale Hankins (10)

University of California

Lawrence Livermore Laboratory

Livermore, CA 94550

A. W. Blackstock (10)

Los Alamos Scientific Laboratory

P.0. Box 1663

Los Alamos, NM 87544

Klaus Becker (10)

Oak Ridge Nationa 1 Laboratory

Health Physics Division

P.0. Box X

Oak Ridge, TN 27830

Bill Swanson (10)

Stanford Linear Accelerator Center

P.0. Box 4349

Stanford, CA 94305

Margarete Ehrlich (10)

National Bureau of Standards

Washington, DC 20545

R. S. Caswe $11(10)$

National Bureau of Standards

Washington, DC 20545
Technical Information Center (179)

No. of

Copies

ONSITE

2 B. J. Melton ERDA Richland Operations Office

1 G. E. Backman Atlantic-Richfield Hanford Company

1 C. D. Corbit United Nuclear Industries, Inc.

I R. 0. Budd Westinghouse Hanford Company

129 Battel le-Northwest

E. L. Alpen

J. P. Corley

G. W. R. Endres (10)

Leo Faust (10)

H. V. Larson

C. M. Unruh (100)

Technical Information (5)

Technical Publications 